\title{
Parameterization of a bucket model for soil-vegetation-atmosphere modeling under seasonal climatic regimes
}

\author{
N. Romano, M. Palladino, and G. B. Chirico \\ Department of Agricultural Engineering and Agronomy, University of Napoli Federico II, Portici (Napoli), Italy
}

Received: 15 May 2011 - Published in Hydrol. Earth Syst. Sci. Discuss.: 24 May 2011

Revised: 24 November 2011 - Accepted: 25 November 2011 - Published: 21 December 2011

\begin{abstract}
We investigate the potential impact of accounting for seasonal variations in the climatic forcing and using different methods to parameterize the soil water content at field capacity on the water balance components computed by a bucket model (BM). The single-layer BM of Guswa et al. (2002) is employed, whereas the Richards equation (RE) based Soil Water Atmosphere Plant (SWAP) model is used as a benchmark model. The results are analyzed for two differently-textured soils and for some synthetic runs under real-like seasonal weather conditions, using stochasticallygenerated daily rainfall data for a period of 100 years. Since transient soil-moisture dynamics and climatic seasonality play a key role in certain zones of the World, such as in Mediterranean land areas, a specific feature of this study is to test the prediction capability of the bucket model under a condition where seasonal variations in rainfall are not in phase with the variations in plant transpiration. Reference is made to a hydrologic year in which we have a rainy period (starting 1 November and lasting 151 days) where vegetation is basically assumed in a dormant stage, followed by a drier and rainless period with a vegetation regrowth phase. Better agreement between BM and RE-SWAP intercomparison results are obtained when BM is parameterized by a field capacity value determined through the drainage method proposed by Romano and Santini (2002). Depending on the vegetation regrowth or dormant seasons, rainfall variability within a season results in transpiration regimes and soil moisture fluctuations with distinctive features. During the vegetation regrowth season, transpiration exerts a key control on soil water budget with respect to rainfall. During the dormant season of vegetation, the precipitation regime becomes an important climate forcing. Simulations also highlight the occurrence of bimodality in the probability distribution of soil
\end{abstract}

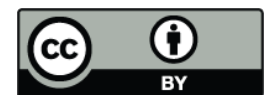

Correspondence to: N. Romano (nunzio.romano@unina.it) moisture during the season when plants are dormant, reflecting that soil, it being of coarser or finer texture, can be preferentially in either wetter or drier states over this period.

\section{Introduction}

Progress has been achieved in advancing scientific knowledge on the interactions within the soil-vegetationatmosphere (SVA) system and also in developing improved monitoring and modeling technologies. However, there is still little information transferred from the research world to the tools used by public agencies, consultants, and stakeholders responsible for managing land and water resources. On the one hand, hydrologic models developed by scientists are usually very complex and require large amounts of specialized input data that may not be directly available (Höllander et al., 2009). On the other hand, simple models are easy to use, but may be of inadequate accuracy or detail to answer specific management questions, especially in cases of multiple demands upon the SVA system.

With specific reference to soil-water/vegetation interactions, the Richards equation (RE) offers a comprehensive, physics-based description of water movement in the vadose zone and associated hydrologic fluxes, including root water uptake (Lee and Abriola, 1999; Feddes et al., 2001). This model is a parabolic, partial differential equation whose parameters are the soil water retention, $\theta(h)$, and hydraulic conductivity, $K(h)$ [or, $K(\theta)$ ], functions, the so-called soil hydraulic properties, that are relationships between matric suction head, $h$, soil water content, $\theta$, and hydraulic conductivity, $K$ (Kutílek and Nielsen, 1994). Solutions of the Richards equation are difficult because of the strong nonlinearity of the functions $\theta(h)$ and $K(h)$. One can achieve RE solutions in analytical or semi-analytical terms only for particular types of soils (e.g. linear soils) and specific boundary conditions, instead one has to resort to numerical methods for solving

Published by Copernicus Publications on behalf of the European Geosciences Union. 
accurately most of practical soil-water flow problems (Romano et al., 1998; Šimůnek et al., 2008). Employing RE at laboratory soil core or field plot scales can be done with confidence (Sposito, 1986), but may become unmanageable for hydrologic applications at the scales of hillslopes and catchments chiefly because of the spatial, and sometimes also temporal, variability exhibited by the soil hydraulic properties (Sharma and Luxmoore, 1979; Braud, 1998; Settin et al., 2007), and partly because of theoretical doubts that capillary suction heads and hydraulic gradients are still the driving forces of mass flow and momentum transfer in unsaturated porous media at such larger scales (Beven, 1989; McDonnell et al., 2007). Notwithstanding these limitations, RE is increasingly being used in process-based distributed models of hydrological cycle and is also used at the global scale in Land Surface Models (Kowalczyk et al., 2006; Clark et al., 2008; Manus et al., 2009; Oleson et al., 2010). Moreover, RE solutions are anyhow considered as the best available reference for comparisons to the performances of simplified models to be categorized in terms of their complexity with respect to the number of hydrologic processes employed (Guswa et al., 2002).

The soil water balance bucket model (BM) of Manabe (1969) is the classic example of a lumped model accounting for a simplified description of the major processes evolving in the hydrologic cycle, in which a single soil layer is conceptualized as a bucket receiving and retaining all incident water until its storage capacity is filled. The latter assumption, for example, saves one the need of describing infiltration rate with respect to rainfall intensity through an analytical (usually, empirical) equation. This type of model is particularly efficient to describe land surface processes and thus extensively used when coupled with large scale atmospheric models, including General Circulation Models (GCMs), but may experience problems due to its simple representation of vegetation and estimation of potential evapotranspiration fluxes (Seneviratne et al., 2010). Since the valuable function of soil to transfer water with different rates along the vertical profile is virtually ignored and a direct feedback is described between soil water storage and evapotranspiration, BM is characterized by a rather short soil water storage memory and can hardly describe correctly the system response to rapid time evolution in atmospheric forcing. Yet, in the last decades several studies have shown that bucket models can be efficiently employed for predicting some components of the soil water budget, as they provide results similar to those observed in the field or those simulated with models which are more detailed in the description of the soil water dynamics, at least in soils with specific climatic regimes (Milly, 1994; Guswa et al., 2002; Farmer et al., 2003).

On the wave of studies gaining insights into the potential impacts that land use and climate changes may exert on catchment scale hydrologic response, one challenging question is to obtain efficient predictions while recognizing that water transfer in the SVA continuum is controlled by several non-linear and dynamic interacting processes (Blöschl and Montanari, 2010). The efficiency of simplified models has been tested in areas characterized by stationary condition of the climatic forcing (Milly et al., 2008), which can be observed only in limited zones of the World, such as in the savannas of South Africa (Porporato et al., 2002). Instead, transient soil-moisture dynamics and climatic seasonality play a key role in other environments (Settin et al., 2007), such as those characterized by Mediterranean climates, where rainfall shows an out-of-phase relationship with air temperature, with an alternation of wet-cold and dry-warm periods. The end of wet-cold period corresponds to the beginning of the growing season, when water dynamics are mainly controlled by the evapotranspiration processes, which induce a progressive reduction of the water stored toward the dry-warm season. The soil-moisture dynamics during the growing season is generally far from what can be predicted with the hypothesis of stationarity. Nevertheless, under such complex climatic variability during the year, linking the fluxes and vegetation growth to the variations in soil water contents along the entire soil profile can be a prerequisite to adequately simulate fluctuations in evapotranspiration or other hydrologic fluxes.

A general objective of the present work is to assess the validity of using a bucket model to simulate the local water balance and associated fluxes assuming a rainfall regime and vegetation characteristics representative of Mediterranean areas. Comparisons are carried out with respect to the results obtained under the same conditions through a REbased hydrologic model. Under climate, vegetation, and soil conditions relevant to an African savannah site, Guswa et al. (2002) have shown that an appropriate formulation of the single-layer bucket model, with proper account of the relationship between transpiration, $T$, and degree of saturation in soil, $s$, can provide results similar to those obtained by a more comprehensive model based on the integration of the vertically discretized Richards equation. At relatively larger timescale, namely an entire growing season of 200 days, Table 5 of this paper reports some more similarity among the water fluxes as computed by the RE or BM models. However, when moving to a smaller time-scale, namely the daily timescale, discrepancies between RE model results and those of the BM of Guswa et al. (2002) were about $50 \%$ for evapotranspiration flux, ET, and ranged from $50 \%$ to $70 \%$ over a season for the $T / E T$ ratio (see, for example, the traces of daily transpiration depicted in Fig. 8 of that paper).

The soil water content at the condition of field capacity, $\theta_{\mathrm{fc}}$ (field capacity, for short), is a key parameter of a bucket-type approach as it represents a threshold water content that controls the processes of surface runoff generation and drainage (leakage) out of the root zone (more precisely, out of the lower boundary of the flow domain). The classic bucket approach is thus unable to manage an infiltration excess runoff (the Hortonian mechanism of runoff generation) and subsurface flow, and handles only a saturation excess runoff (Dunne mechanism). When soil water storage in the bucket exceeds 
field capacity, then this excess of water is routed to runoff only, or to both runoff and drainage. Notwithstanding the considerable importance of field capacity in a bucket-type hydrologic approach, its value is still determined using simplified, often very inaccurate techniques (Romano and Santini, 2002). In view of parameterizing a bucket model for effectively computing the soil water budget under environmental conditions representative of a Mediterranean area, a specific objective of this study is to evaluate whether the determination of the field capacity value with an appropriate technique can lead to BM results more in agreement with those offered by a more complex model based on RE.

\section{Description of the models}

\subsection{The SWAP model}

SWAP (Soil, Water, Atmosphere and Plant) is a widespread used model in the soil hydrology community to simulate soil water flow in the vadose zone at field scale and during entire growing seasons (van Dam et al., 2008). The vertical soilwater movement is described by the Richards equation with a sink term accounting for the root water uptake, as follows:

$C(h) \frac{\partial h(z, t)}{\partial t}=\frac{\partial}{\partial z}\left\{K(h)\left[\frac{\partial h(z, t)}{\partial z}-1\right]\right\}-S(h)$

which is written here in its pressure-head form. In Eq. (1), time, $t$, and vertical coordinate, $z$ (taken positive downward), are the independent variables, whereas suction pressurehead, $h$, is the dependent variable. Model parameters are the water capacity function, $C(h)=d \theta / d h$, which can be readily obtained from knowledge of the soil water retention function, $\theta(h)$, and the hydraulic conductivity function, $K[\theta(h)]$. After having specified the appropriate initial and boundary conditions, the SWAP model solves Eq. (1) numerically using a finite-difference approach.

The following van-Genuchten/Mualem analytical relationships are used as soil hydraulic properties:

$$
\begin{aligned}
& s_{\mathrm{e}}(h)=\frac{\theta-\theta_{\mathrm{r}}}{\theta_{0}-\theta_{\mathrm{r}}}=\left[\frac{1}{1+\left(\alpha_{\mathrm{VG}} \cdot h\right)^{n_{\mathrm{VG}}}}\right]^{m_{\mathrm{VG}}} \\
& K(\theta)=K_{0} S_{\mathrm{e}}^{\tau_{\mathrm{VG}}}\left[1-\left(1-S_{\mathrm{e}}^{1 / m}\right)^{m}\right]^{2}
\end{aligned}
$$

where $\theta_{0}$ is the volumetric water content at $h=0$ (commonly the saturated water content, $\theta_{\mathrm{s}}$ ), $\theta_{\mathrm{r}}$ is the residual water content, namely the water content $\theta$ for $h$ at $+\infty, K_{0}$ is the hydraulic conductivity when $h=0, \alpha_{\mathrm{VG}}$ is a scale parameter, whereas $n_{\mathrm{VG}}, m_{\mathrm{VG}}=\left(1-1 / n_{\mathrm{VG}}\right)$, and $\tau_{\mathrm{VG}}$ are shape parameters. In principle, parameter $\theta_{0}$ should be viewed as distinct from the saturated water content, $\theta_{\mathrm{s}}$, mainly because of possible air entrapment in the soil pores. The term $s_{\mathrm{e}}\left(0 \leq s_{\mathrm{e}} \leq 1\right)$ is the effective degree of soil saturation (simply, effective saturation).

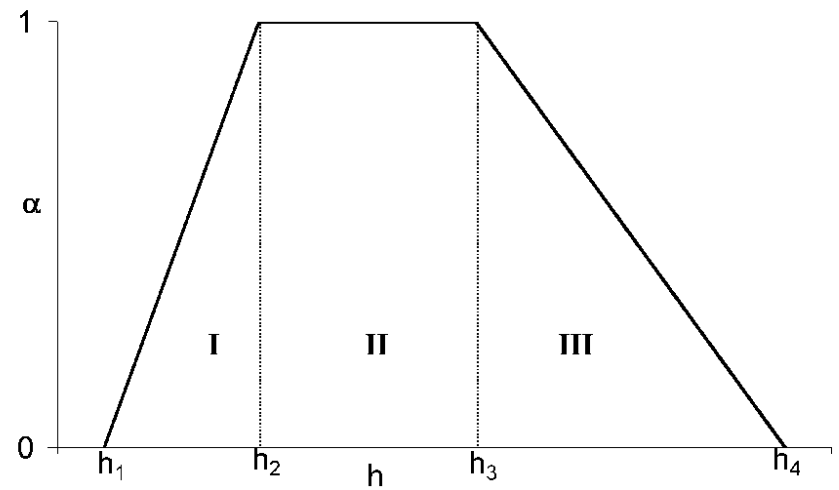

Fig. 1. Root water uptake reduction function, as implemented in SWAP, after van Dam et al. (2008).

In SWAP, the sink term, $S(h)$, describes the extraction of water by the root architecture at the point macroscopic scale as a function of suction pressure head, $h(z, t)$. Specifically, root water uptake rate at a given soil depth, $z$, is determined by the normalized root density distribution at this depth, $\beta(z, t)$, and the maximum transpiration rate, $T_{\max }$, whereas reductions due to water stresses are described by the uptake reduction function, $\alpha(h)(0 \leq \alpha \leq 1)$, such that $S(h)=\beta(z, t) \cdot \alpha(h) \cdot T_{\max }$ (Kroes and van Dam, 2003). Under conditions of no stress, the sink term represents the maximum uptake rate as follows: $S_{\mathrm{p}}=\beta(z, t) \cdot T_{\max }$.

For computing evapotranspiration fluxes, SWAP follows a macroscopic approach and uses the Penman-Monteith equation with daily weather data such as air temperature, solar radiation, wind speed and humidity; a minimum value for canopy and aerodynamic resistance is applied. Maximum transpiration rates are computed taking also the evaporation rate of the water intercepted by the vegetation into account. Actual evapotranspiration rates are computed using a reduction factor based on root water uptake and a reduction factor due to maximum soil evaporation flux according to Darcy's law. The actual transpiration rate is then calculated on the basis of the actual soil water extraction rate over the whole rooting depth. Further details on this module of the model can be found in Kroes and van Dam (2003) and van Dam et al. (2008). Of specific interest for this study is the semi-empirical way with which the uptake reduction function, $\alpha(h)$, is modeled by SWAP (see Fig. 1). Not accounting for salinity problems, this reduction function can be basically split into three different parts of the diagram (see Eq. 3): Part-I is for $h_{1} \leq h<h_{2}$ and represents air deficiency; Part-II is for $h_{2} \leq h \leq h_{3}$ and accounts for a conditions of no water stress; finally, Part-III is for $h_{3}<h \leq h_{4}$ and reveals water stress conditions. Matric suction head $h_{4}$ is the well-known permanent wilting point of the vegetation, $h_{\mathrm{w}}$. 


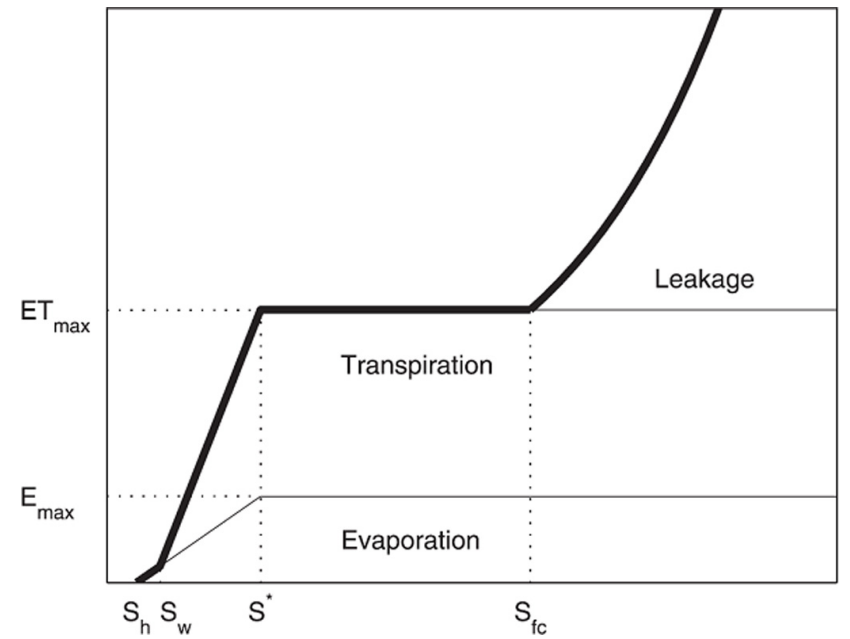

Fig. 2. Loss functions $E(s), T(s)$, and $L(s)$ as average degree of soil saturation, $s$, changes in the bucket model due to evaporation, transpiration, and leakage (redrawn from Guswa et al., 2002).

$\alpha(h)=\left\{\begin{array}{lll}0 & , & 0 \leq h<h_{1} \\ \frac{h-h_{1}}{h_{2}-h_{1}} & , & h_{1} \leq h<h_{2} \\ 1 & , & h_{2} \leq h \leq h_{3} \\ 1-\frac{h-h_{3}}{h_{4}-h_{3}}, & , & h_{3}<h \leq h_{4} \\ 0 \quad & , & h_{4}<h<+\infty\end{array}\right.$

According to the results by Denmead and Shaw (1962), the value of $h_{3}$ should depend on potential transpiration and hence, strictly speaking, even the dimensionless parameter $\alpha$ depends on the potential transpiration rate.

\subsection{The Bucket model}

In this work we have used the single-layer bucket model proposed by Laio et al. (2001) and modified by Guswa et al. (2002) that describes soil moisture dynamics at the daily time-scale by assuming the soil as a reservoir to be intermittently filled by rainfall events in the form of randomly distributed shots. Soil water storage capacity is emptied by surface runoff, deep drainage, and evapotranspiration processes. For this model, the water balance equation at a point scale for the soil layer of depth $Z_{\mathrm{r}}$ (i.e. the control volume) can be cast as follows:

$n Z_{r} \frac{d s(t)}{d t}=I[s(t), t]-E[s(t)]-T[s(t)]-L[s(t)]$

where $n$ is soil porosity, and $s(0 \leq s \leq 1)$ is the average degree of soil saturation (i.e. the volumetric soil water content, $\theta$, normalized by soil porosity, $n$ ) over the entire rooting zone. In this equation, incoming (positive) and outgoing (negative) fluxes are the rate of rainfall infiltrating into the soil, $I$, the actual evaporation rate, $E$, the actual transpiration rate, $T$, and the drainage (leakage rate) from the bottom end of the bucket, $L$, respectively. Note that evaporation, $E$, transpiration, $T$, and leakage, $L$, rates are considered as function of average soil saturation, $s$, only. Losses due to surface runoff are generated only when the bucket is completely full, i.e. at the condition of full saturation in the soil. Only a fraction of the incoming precipitation is able to infiltrate into the soil when the rainfall depth exceeds the storage capacity of the soil profile. Therefore, the relationship $I[s(t), t]=\min [r$, $\left.n Z_{\mathrm{r}}(1-s)\right]$ accounts for the dependence of infiltration rate, $I$, on rainfall depth, $r$, and the degree of soil saturation, $s$, in the sense that rainfall infiltration is equal either to rainfall depth or to soil storage capacity, whichever is less. Because of a stochastic representation of precipitation, $P(t)$, Eq. (4) is a stochastic linear ordinary differential equation and should be viewed as a probabilistic model of soil water budget.

Evapotranspiration is a fundamental hydrologic process and most bucket models treat only implicitly the effect that vegetation canopy exerts on evapotranspiration. An interesting feature of the bucketing approach proposed by Guswa et al. (2002) is the separation of soil surface evaporation from transpiration by plants. Transpiration, $T(s)$, and evaporation, $E(s)$, as a function of average soil saturation, $s$, are computed through the following relations:

$$
\begin{aligned}
& T(s)=\left\{\begin{array}{lll}
0 & , & s \leq s_{\mathrm{W}} \\
\frac{s-s_{\mathrm{W}}}{s^{*}-s_{\mathrm{W}}} \cdot T_{\max }, & s_{\mathrm{W}}<s<s^{*} \\
T_{\max } & , \quad s \geq s^{*}
\end{array}\right. \\
& E(s)=\left\{\begin{array}{lll}
0 & , & s \leq s_{\mathrm{h}} \\
\frac{s-s_{\mathrm{h}}}{s^{*}-s_{\mathrm{h}}} \cdot E_{\max }, & s_{\mathrm{h}}<s<s^{*} \\
E_{\max } & , & s \geq s^{*}
\end{array}\right.
\end{aligned}
$$

where $s_{\mathrm{W}}$ is the saturation at wilting condition, and $s^{*}$ is saturation at incipient stomata closure; the term $s_{\mathrm{h}}$ is the hygroscopic saturation, namely the average degree of saturation in soil when soil suction at the soil-atmosphere interface is extremely low (this suction head is often set at a value ranging from $150 \times 10^{3} \mathrm{~cm}$ to $500 \times 10^{3} \mathrm{~cm}$ ) and evaporation ceases.

Depletion of soil water due to the uptake by the plant root system is assumed to be governed by the two major mechanisms of atmospheric demand and supply of water in the soil. The model does not account for plant characteristics explicitly. Within this framework, a basic soil parameter is the saturation $s^{*}$ when soil water starts becoming a limiting factor and plants are no longer able to transpire at the full rate $\mathrm{ET}_{\max }$, as the sum of maximum daily evaporation, $E_{\max }$, and maximum daily transpiration, $T_{\max }$ (see Fig. 2 and Eqs. 5-6). When soil water supply is insufficient to meet the atmospheric demand, namely when $s$ is less than $s^{*}$, the progressive leaf stomatal closure yields a reduction in root water uptake and actual transpiration, $T$, start decreasing from $T_{\max }$ to reach the zero value at wilting point, $s_{\mathrm{W}}$, following a linear pattern. Actual evaporation may not equal the evaporation rate under well-watered conditions, $E_{\max }$, and also decreases linearly from $E_{\max }$, at $s=s^{*}$, to zero when $s=s_{\mathrm{h}}$. The difference between the two threshold values of $s_{\mathrm{w}}$ and 
$s_{\mathrm{h}}$ accounts for the fact that evaporation may proceed even after transpiration has stopped at the wilting point of vegetation (Laio et al., 2001). Therefore, for $s$ less than $s_{\mathrm{w}}$, transpiration ceases and evaporation from soil surface remains the sole active component of the evapotranspiration process. Other features of the BM can be found in the paper by Guswa et al. (2002).

\section{Parameterization strategy for evapotranspiration and field capacity}

\subsection{Homogenizing BM and SWAP evapotranspiration functions}

The bucket and SWAP models handle the calculation of evapotranspiration rates in different manner and a sort of equivalence between them should be set in order to make comparisons between model outputs meaningful and more effective.

A first assumption is that the soil is almost completely covered by vegetative canopies so that soil evaporation can be neglected. From a parametric perspective, this is equivalent to assume $s_{\mathrm{h}}=s_{\mathrm{W}}$ in the BM, while for SWAP soil cover fraction, $F_{\mathrm{sc}}$, is set at 1.0 and crop factor, $\kappa_{\mathrm{c}}$, is also set at 1.0. We basically consider that transpiration water losses follow two stages, the constant and falling rate stages, but do not distinguish between low or high transpiration demands. In SWAP, the falling-rate phase of uptake, and hence of transpiration, follows a nonlinear, concave-shaped depletion from $T_{\max }$ to zero (de Jong van Lier et al., 2009). In BM, transpiration as a function of average soil saturation in the root zone is modeled by piecewise linear segments as defined by Eq. (5) and shown in Fig. 2. Therefore, to make evapotranspiration losses of the two models comparable, we impose: $\beta(z, t)=1$ (i.e. uniform root density distribution within the root zone), $s_{\mathrm{W}}=s\left(h_{4}\right)$ (i.e. equivalence of the wilting points) and $h_{1}=h_{2} \approx 0$ (i.e. the effect of the air deficiency negligible). We also set $s^{*}$ such as:

$$
\int_{s_{\mathrm{W}}}^{s^{*}} T(s) \cdot d s+T_{\max }\left(1-s^{*}\right)=T_{\max } \int_{s_{\mathrm{w}}}^{1} \alpha[h(s)] \cdot d s
$$

where $T(s)$ is defined by Eq. (5), while $\alpha(h)$ is defined by Eq. (3). Equation (7) is equivalent to impose the same average transpiration rate in the soil moisture range from the wilting point to the full saturation condition. Equation (7) is verified if $s^{*}$ is defined as follows:

$s^{*}=2\left[1-\int_{s_{\mathrm{W}}}^{1} \alpha[h(s)] \cdot d s\right]-s_{\mathrm{W}}$

Figure 3 shows examples of BM and SWAP transpiration functions after setting parameter $s^{*}$ according to Eq. (8).

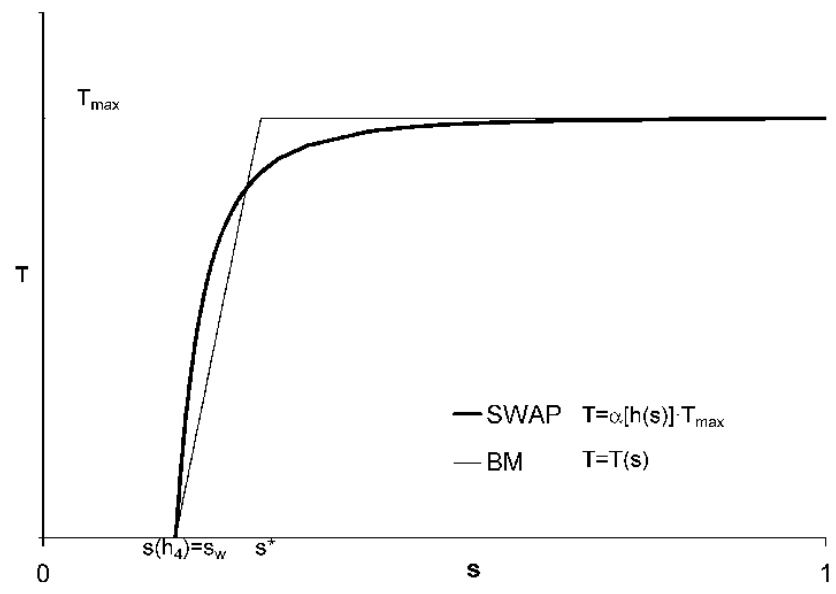

Fig. 3. BM transpiration function as compared with that of SWAP, after imposing the condition expressed by Eq. (7).

\subsection{Techniques for determining field capacity}

Field capacity is defined as the volumetric water content remaining in a uniform soil profile two or three days after having been completely wetted with water and after free drainage beyond the root zone has become negligible (Soil Sci. Soc. Am., 2008). The field capacity concept was originally introduced for irrigation scheduling purposes under a simplistic view of soil water movement in the SVA system (Veihmeyer and Hendrickson, 1927). It was soon used also by hydrologists who defined it as the maximum quantity of water that can be permanently retained in the soil against the pull of gravity (Horton, 1935). In catchment hydrology, field capacity is thus considered as a critical threshold parameter of the water-holding capacity of the soil that affects both runoff generation mechanism and evapotranspiration process. As pointed out by Farmer et al. (2003), the field capacity concept is strictly applicable to the unsaturated zone only and therefore the amount of water held at field capacity will vary as the saturated portion of the soil profile increases or decreases.

Apart from some subjectivity related to the definitions of field capacity, further elements of uncertainty are introduced by the commonly used practice to ascribe this parameter to a specific point of the soil water retention characteristic. Field capacity, $\theta_{\mathrm{fc}}$, is often estimated on a soil sample in the laboratory as the soil water content at the suction pressure of $1 / 3$ bar (about $3.3 \mathrm{~m}$ of suction head), regardless of the specific physical (especially soil texture) and chemical properties of the soil sample. If one would take textural characteristics into account, it is suggested to set the suction head approximately at $1.0 \mathrm{~m}$ for coarser sandy soils and at $5.0 \mathrm{~m}$ for finer clayey soils, whereas the suction head of $3.0 \mathrm{~m}$ (a kind of average between the previous two suction heads) is mostly refereed to medium-textured loamy soils. On the other hand, allowing for the definition of field capacity, Meyer and Gee (1999) 
suggested $\theta_{\mathrm{fc}}$ should be related to the hydraulic conductivity function of a soil and determined from the $K(\theta)$-curve as the water content when $K$ takes on values ranging from $10^{-6} \mathrm{~cm} \mathrm{~s}^{-1}$ to $10^{-8} \mathrm{~cm} \mathrm{~s}^{-1}$. Some authors have proposed relating the negligible drainage flux at field capacity, $q_{\mathrm{fc}}$, to the daily evapotranspiration for the area of interest (Kutílek and Nielsen, 1994), whereas Laio et al. (2001) defined the field capacity point when drainage losses $\left(K_{\mathrm{s}}\right.$ in practice, under the unit hydraulic gradient assumption) are $10 \%$ of the maximum daily evapotranspiration losses, $\mathrm{ET}_{\max }$.

Whatever the pre-fixed points of the $\theta(h)$ or $K(\theta)$ functions, soil water content at field capacity is certainly not an inherent soil property, but rather is a process-dependent parameter that may represent only a rough attempt to summarize a dynamic flow process through a single global static coefficient (Romano and Santini, 2002). The redistribution process in soil, and hence the field capacity value, depends on the water content distribution established in the entire soil profile at the end of the preceding infiltration phase, as well as on the boundary conditions of the flow domain. In case of coarser-textured soils with stable aggregates, the field capacity concept is underpinned by experimental evidence since for these types of soils the drainage process is relatively very fast initially, but then its rates decrease drastically due to the abrupt reduction in unsaturated hydraulic conductivities as suction pressure head increases. Therefore, Romano and Santini (2002) argued that a field drainage experiment is the test to be preferred for determining the water content value at field capacity, namely the condition when drainage fluxes become virtually nil during a redistribution process started from an initially saturated soil profile and with no flux from the soil surface. Using the HYDRUS-1D software to simulate field drainage experiments for real soils retrieved from different soil databases, Twarakavi et al. (2009) confirmed the inaccuracy of determining field capacity from pre-fixed points of the water retention curve. They also suggested that the value of $0.01 \mathrm{~cm} \mathrm{day}^{-1}$ can be considered as a negligible drainage flux being imposed at the lower limit of the rooting zone to meet the condition of field capacity for a wide range of soils. Moreover, these authors developed an empirical analytical relationship to estimate $\theta_{\mathrm{fc}}$ from information about the soil hydraulic properties.

Especially for practical applications, when judging on the effectiveness of a method with respect to another (for example, a simplified one) it is important not only to evaluate the discrepancies among parameter values obtained from different methods (parametric evaluation), but also to analyze the outputs of a hydrologic model computed by using different parameterization techniques (functional evaluation). Under soil, vegetation, and climate conditions representative of a Mediterranean area, a focus here is to compare, with respect to the reference model output, the soil-water budget predictions of BM when field capacity is estimated by using either a standard pre-fixed point of the $\theta(h)$ curve or a field transient drainage experiment.
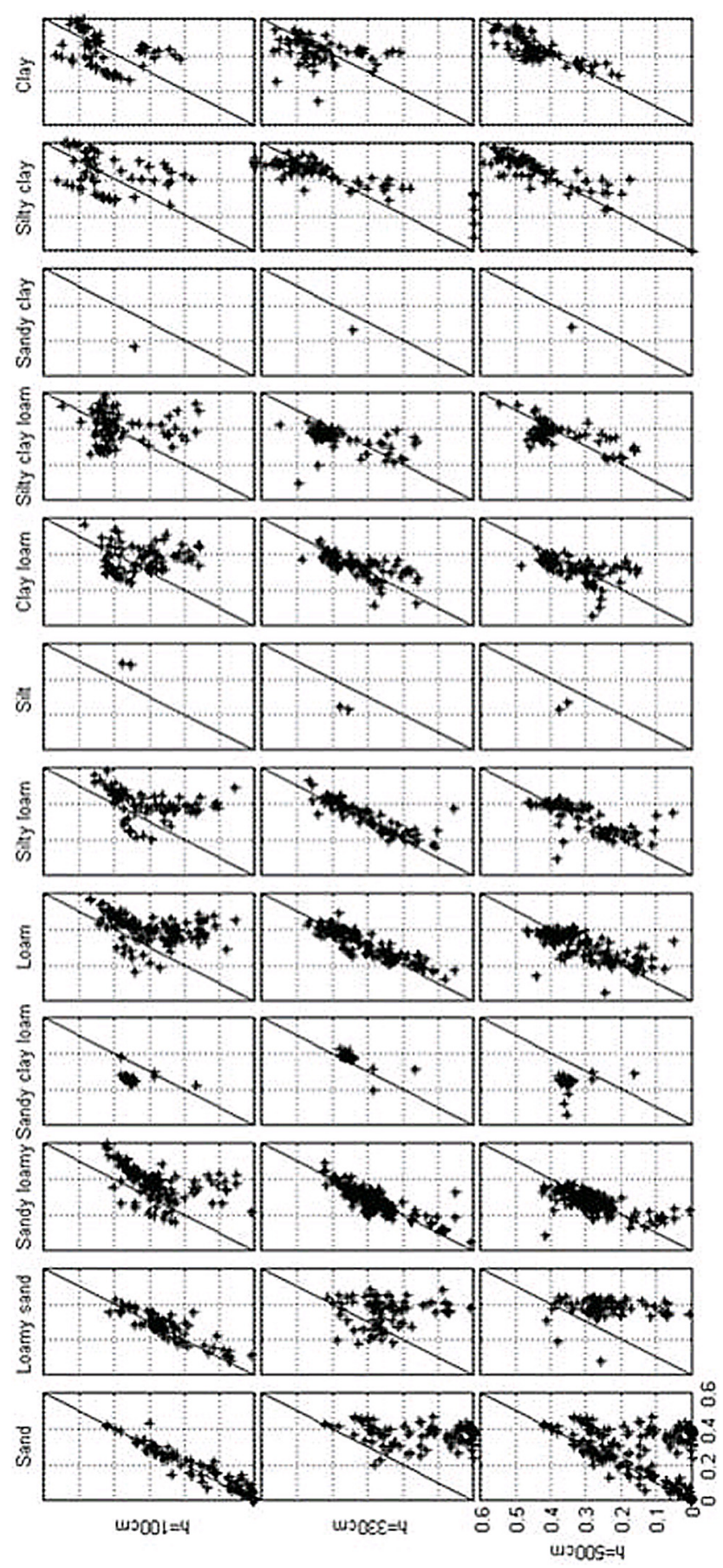

Fig. 4. Scatter plots of field capacity, $\theta_{\text {fc_drain }}$, as determined by the drain-method versus field capacity values obtained from the water retention characteristics by the fix-method, $\theta_{\mathrm{fc} \_ \text {fix }}$, for the three suction heads of $100 \mathrm{~cm}, 330 \mathrm{~cm}$, and $500 \mathrm{~cm}$. Data points refer to 1087 soil samples grouped according to different textural classes.

\section{Soil, vegetation, and climatic characteristics}

Analyses were carried out in this study using various soil properties retrieved from the UNSODA database and 


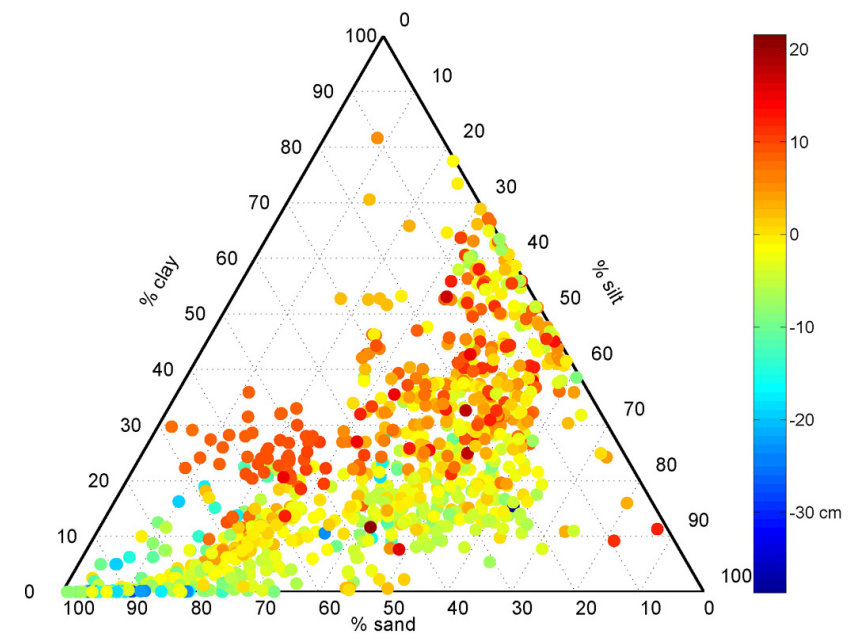

Fig. 5. Ternary diagram of the soil texture triangle showing markers whose color depends on the magnitude of variable $\triangle \mathrm{PAWS}_{\max }$ being the difference between the maximum plant-available soil-water holding capacity when field capacity is alternatively determined using the drain- or fix-method.

gathered from different zones of the World (Nemes et al., 2001) as well as stored in the database of the Soil Hydrology Laboratory of University of Naples Federico II and mainly collected in various parts of Southern Italy (Ceres et al., 2010). On the whole, we have processed data from 1087 soils. Synthetic transient drainage experiments (referred to as drain-method) have been performed to determine the average soil water content, $\theta_{\text {fc_drain }}$, in the soil profile when the drainage rate is $q_{\text {drain }}=0.010 \mathrm{~cm} \mathrm{day}^{-1}$ at the soil depth $z_{\mathrm{r}}=1.0 \mathrm{~m}$ and imposing a zero flux boundary condition at the soil surface (Romano and Santini, 2002). For the same soils, field capacity $\left(\theta_{\mathrm{fc} \_ \text {fix }}\right)$ was also calculated from the respective water retention functions (referred to as fix-method) as the water content at the fixed suctions heads of $100 \mathrm{~cm}$, $330 \mathrm{~cm}$, and $500 \mathrm{~cm}\left(\theta_{\mathrm{fc}_{-} \text {fix }-100}, \theta_{\mathrm{fc}_{-} \text {fix }-330}\right.$, and $\left.\theta_{\mathrm{fc} \_ \text {fix }-500}\right)$.

Using the entire available dataset and for different soil textural classes, the scatter plots of Fig. 4 provide a qualitative assessment of correlations between variables $\theta_{\mathrm{fc} \_d r a i n}$ (horizontal axis) and the three different variables $\theta_{\mathrm{fc} \_ \text {fix }}$ (vertical axes). A 1:1 line is also drawn in each plot to make it easier detecting possible better agreements among the variables. The scatter plots arranged along the principal diagonal of this kind of matrix diagram (i.e. from the topleft corner to the bottom-right corner of Fig. 4) confirm the higher degree of correlation of $\theta_{\mathrm{fc} \_ \text {drain }}$ with $\theta_{\mathrm{fc} \_ \text {fix }-100}$ for coarser soils, with $\theta_{\mathrm{fc} \_ \text {fix }-330}$ for medium-textured soils, and with $\theta_{\mathrm{fc} \_ \text {fix }-500}$ for finer soils, respectively (Ceres, 2009). Let PAWS $_{\max }=\left(s_{\mathrm{fc}}-s_{\mathrm{W}}\right) \times n \times Z_{\mathrm{r}}$ be the maximum plantavailable soil-water holding capacity. Then, Fig. 5 illustrates a ternary diagram with relative intensity of each colored dots depending on the magnitude of the difference $\triangle \mathrm{PAWS}_{\max }=$ $\mathrm{PAWS}_{\text {max_drain }}-\mathrm{PAWS}_{\max \_ \text {fix }}$ when using the $s_{\mathrm{fc} \_ \text {drain }}$ and

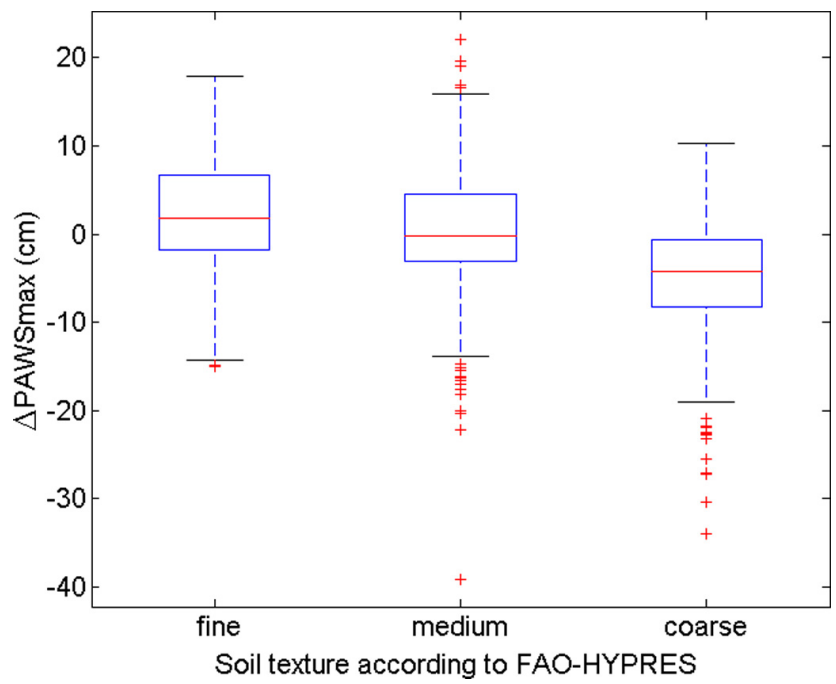

Fig. 6. Boxplots of variable $\triangle \mathrm{PAWS}_{\max }$ for the soils of the fine, medium, and coarse soil texture classification according to the FAOHYPRES.

$s_{\mathrm{fc} \_ \text {fix }}$ values to compute variable PAWS $S_{\max }$. This diagram provides a more quantitative evaluation of the differences among the soils employed in this study and helps in finding suitable representative soil samples for the subsequent analyses being carried out in this study. To further proceed in selecting representative soils, we have also grouped all of the 1087 soils according to the classes of the FAO-HYPRES soil textural triangle (Nemes et al., 1999) and computed the boxplots of variable $\triangle \mathrm{PAWS}_{\max }$ for the soils pertaining to the fine, medium, and coarse textural classes (see Fig. 6). The boxplot for the coarse soil class shows a median approximately of $-4.3 \mathrm{~cm}$, whereas that one for the fine soil class shows a median approximately of $+1.8 \mathrm{~cm}$. With a view to the general aim of this study and based on the results depicted in Figs. 4 to 6, we have considered the soils of the Mediterranean area of Southern Italy and selected a loamy-sand soil as representative of coarse soils and a clay soil as representative of fine soils. The major characteristics of these two soil types are presented in the following (see also Table 1).

The physical properties of the loamy-sand soil are as follows: bulk density of $1.198 \mathrm{~g} \mathrm{~cm}^{-3}$, and USDA percentages of sand, silt, and clay content equal to $73.78 \%, 23.27 \%$, and $2.95 \%$, respectively. For the clay soil, the physical properties are as follows: bulk density of $1.348 \mathrm{~g} \mathrm{~cm}^{-3}$, and USDA percentages of sand, silt, and clay content equal to 21.20 , 31.80 , and 47.00 , respectively. For these two differently textured soils, undisturbed soil cores were subjected to evaporation experiments to obtain the respective parameters of the soil water retention, $\theta(h)$, and hydraulic conductivity, $K\left(s_{\mathrm{e}}\right)$, through an optimization technique (Romano and Santini, 1999). The optimized hydraulic parameter values of Eqs. (2) are reported in Table 1. 
Table 1. Parameters of the van Genuchten-Mualem soil hydraulic relations for the two differently-textured soils used in this study.

\begin{tabular}{lcccccc}
\hline Soil texture & $\begin{array}{c}\theta_{\mathrm{r}} \\
(-)\end{array}$ & $\begin{array}{c}\theta_{\mathrm{s}} \\
(-)\end{array}$ & $\begin{array}{c}\alpha_{\mathrm{VG}} \\
\left(\mathrm{cm}^{-1}\right)\end{array}$ & $\begin{array}{c}n_{\mathrm{VG}} \\
(-)\end{array}$ & $\begin{array}{c}K_{0} \\
\left(\mathrm{~cm} \mathrm{day}^{-1}\right)\end{array}$ & $\begin{array}{c}\tau_{\mathrm{VG}} \\
(-)\end{array}$ \\
\hline Loamy-sand, LS & 0.036 & 0.447 & 0.025 & 1.391 & 86.8 & -1.0 \\
Clay, Cl & 0.061 & 0.426 & 0.0050 & 1.226 & 8.81 & -1.0 \\
\hline
\end{tabular}

Table 2. BM hydrologic parameters.

\begin{tabular}{lccccccc}
\hline Soil texture & $\begin{array}{c}\text { Vegetative } \\
\text { phase }\end{array}$ & $\begin{array}{c}s_{\mathrm{h}}=s_{\mathrm{W}} \\
(-)\end{array}$ & $\begin{array}{c}s^{*} \\
(-)\end{array}$ & $\begin{array}{c}Z_{\mathrm{r}} \\
(\mathrm{cm})\end{array}$ & $\begin{array}{c}\mathrm{ET}_{\max } \\
\left(\mathrm{cm} \mathrm{day}^{-1}\right)\end{array}$ & $\begin{array}{c}\lambda \\
\left(\mathrm{day}^{-1}\right)\end{array}$ & $\begin{array}{c}\eta \\
(\mathrm{cm})\end{array}$ \\
\hline Loamy-sand, LS & $\mathrm{RVP}$ & 0.169 & 0.240 & 100 & 0.46 & 0.195 & 0.595 \\
& DVP & 0.169 & 0.240 & 100 & 0.20 & 0.493 & 0.701 \\
& & & & & & & \\
Clay, Cl & $\mathrm{RVP}$ & 0.460 & 0.590 & 100 & 0.46 & 0.195 & 0.595 \\
& DVP & 0.460 & 0.590 & 100 & 0.20 & 0.493 & 0.701 \\
\hline
\end{tabular}

Results from the simulation runs are as follows: $s_{\mathrm{fc} \_d r a i n, L S}=0.510$ for the loamy-sand soil, and $s_{\mathrm{fc} \_d r a i n, C l}=$ 0.830 for the clay soil. Instead, adopting the simplified method (referred to as fix-method) of estimating the degree of soil saturation at the field capacity from pre-fixed points of the soil water retention function (see Table 1 for the water retention parameters), we obtained the following values: $s_{\mathrm{fc} \_ \text {fix }, \mathrm{LS}}=0.670$ for the loamy-sand soil at the suction head of $100 \mathrm{~cm}$, and $s_{\mathrm{fc} \_ \text {fix }, \mathrm{Cl}}=0.790$ for the clay soil at the suction head of $500 \mathrm{~cm}$. The choice of these two suction heads for computing $s_{\mathrm{fc} \_ \text {fix }}$ for the coarser soil and the finer soil stems from the results we have presented in Fig. 4.

For both hydrologic models, the control volume is an active soil profile with a depth of $1.00 \mathrm{~m}$. Therefore, for the bucket model the depth of rooting zone, $Z_{\mathrm{r}}$, is $1.00 \mathrm{~m}$. The porosity values are $n_{\mathrm{LS}}=0.447$ for the loamy-sand soil and $n_{\mathrm{Cl}}=0.426$ for the clay soil. The product $n Z_{\mathrm{r}}$ represents the so-called active soil depth, which is the volume per unit surface area available for water storage.

For the SWAP model, the lower limit of the root zone is set at a depth of $1.00 \mathrm{~m}$ and the entire soil profile was split in three portions accounting for the numerical discretization of the flow domain: the first uppermost portion of $0.10 \mathrm{~m}$ in thickness comprises 10 compartments; the second interposed portion of $0.40 \mathrm{~m}$ in thickness comprises 8 compartments, and the third lowermost portion of $0.50 \mathrm{~m}$ in thickness comprises 5 compartments. The hydraulic properties of the two different uniform soils are identified by the parameters of Table 1.

Precipitation and transpiration from vegetation are usually out of phase in Mediterranean-type climates being characterized by warm and dry summers, during which vegetation is often under stress conditions, followed by colder and wet winters where precipitations are predominant and air temperatures are relatively mild. With reference to a hydrologic year starting on 1 November, we assumed vegetation dormancy (Dormant Vegetation Phase, DVP) during a wetter rainy period lasting 151 days (from 1 November to $31 \mathrm{March}$ ), and the subsequent vegetation regrowth (Regrowth Vegetation Phase, RVP) during a drier and rainless period lasting 214 days (from 1 April to 31 October). During the wetter season, rainfall volume exceeds evapotranspiration losses, thus soil "bucket" tends to be filled close to the field capacity. During the drier season, in spring vegetation starts leafing out and exhausting soil water storage by transpiration, and when summer is coming transpiration is regulated by the leaf stomatal closures as atmospheric demand increases more and more.

Viola et al. (2008) suggested that in a Mediterranean ecosystem soil moisture dynamics can be effectively investigated by representing the climatic forcing during the year as a sequence of a wet and a dry period, each characterized by a stationary rainfall regime. We considered a Mediterranean woodland ecosystem comprising the following deciduous species: Quercus pubescens Willd., Acer campestre L., and Fraxinus ornus L. For this woody area, values of maximum evapotranspiration, $\mathrm{ET}_{\max }$, are set constant during each season: at $0.46 \mathrm{~cm} \mathrm{day}^{-1}$ during the RVP season, and $0.20 \mathrm{~cm} \mathrm{day}^{-1}$ during the DVP season (Pumo et al., 2008).

To evaluate the impact of the seasonal evolution of rainfall intensity on soil moisture dynamics, the occurrence of precipitation in time, $P(t)$, has been probabilistically described using a Poisson Rectangular Pulse (PRP) model on a daily time scale with probability of occurrence equal to $\lambda(t) d t(d t=1$ day). The Poisson process of arrival rate $\lambda$ 
Table 3. SWAP hydrologic parameters.

\begin{tabular}{lcccccccc}
\hline Soil texture & $\begin{array}{c}\text { Vegetative } \\
\text { phase }\end{array}$ & $\begin{array}{c}h_{1}=h_{2} \\
(\mathrm{~cm})\end{array}$ & $\begin{array}{c}h_{3} \\
(\mathrm{~cm})\end{array}$ & $\begin{array}{c}h_{4}=h_{\mathrm{W}} \\
(\mathrm{cm})\end{array}$ & $\begin{array}{c}Z_{r} \\
(\mathrm{~cm})\end{array}$ & $\begin{array}{c}\mathrm{ET}_{\max } \\
\left(\mathrm{cm} \mathrm{day}^{-1}\right)\end{array}$ & $\begin{array}{c}F_{\mathrm{sc}} \\
(-)\end{array}$ & $\begin{array}{c}\kappa_{\mathrm{c}} \\
(-)\end{array}$ \\
\hline Loamy-sand, LS & RVP & 1.0 & 300 & 16000 & 100 & 0.46 & 1.0 & 1.0 \\
& DVP & 1.0 & 300 & 16000 & 100 & 0.20 & 1.0 & 1.0 \\
& & & & & & & & \\
Clay, Cl & RVP & 1.0 & 1500 & 16000 & 100 & 0.46 & 1.0 & 1.0 \\
& DVP & 1.0 & 1500 & 16000 & 100 & 0.20 & 1.0 & 1.0 \\
\hline
\end{tabular}

Table 4. Relative soil moisture at field capacity, $s_{\mathrm{fc}}$, for BM and soil-water storage capacity, $\mathrm{WS}_{\mathrm{ini}}$, in the system at the start of the simulation run.

\begin{tabular}{llcc}
\hline Soil texture & Method & $s_{\mathrm{fc}}(-)$ & $\mathrm{WS}_{\text {ini }}(\mathrm{cm})$ \\
\hline \multirow{2}{*}{ Loamy-sand, LS } & drain (drainage exp.) & 0.510 & 22.80 \\
& fix (from Eq. 2a at $h=100 \mathrm{~cm})$ & 0.670 & 29.95 \\
Clay, Cl & drain (drainage exp.) & 0.830 & 35.36 \\
& fix (from Eq. 2a at $h=500 \mathrm{~cm})$ & 0.790 & 33.65 \\
\hline
\end{tabular}

(in number of storms per day) does not account for the temporal structure within each rainfall event, whereas the distribution of storm depth is exponential with a mean depth of $\eta$ (in cm per storm). Following Pumo et al. (2008), the selected PRP parameter values are: $\lambda_{\mathrm{RVP}}=0.195 \mathrm{day}^{-1}$ and $\eta_{\mathrm{RVP}}=0.595 \mathrm{~cm}$ for the RVP period; $\lambda_{\mathrm{DVP}}=0.493 \mathrm{day}^{-1}$ and $\eta_{\mathrm{DVP}}=0.701 \mathrm{~cm}$ for the DVP period.

\subsection{Overview of input parameters for BM and SWAP - initial and boundary conditions}

To summarize the parameterization strategy employed for the bucket model and the Richards equation based SWAP model discussed in the previous sections, Tables 2, 3, and 4 reports the various parameter values selected for the two different models (Tables 2 and 3, respectively) and for the two differently textured soils (the loamy-sand soil and the clay soil, respectively).

In view of one specific objective of the present study, Table 4 reports the values of relative soil moisture at the condition of field capacity for the loamy-sand and the clay soils when adopting the drain-method or the fix-method (Romano and Santini, 2002).

Simulation runs have been carried out using one timeseries of synthetic daily rainfall records generated stochastically for a 100-year-long period, obtained by combining two different Poisson Rectangular Pulse (PRP) models, for the regrowth (RVP) and dormant vegetation (DVP) phases, respectively. Table 2 reports the PRP parameters for the RVP and DVP periods whereas, as an example, Fig. 7 shows for a generic year the rainfall sequences generated with the PRP model for these two seasons of the hydrologic year.

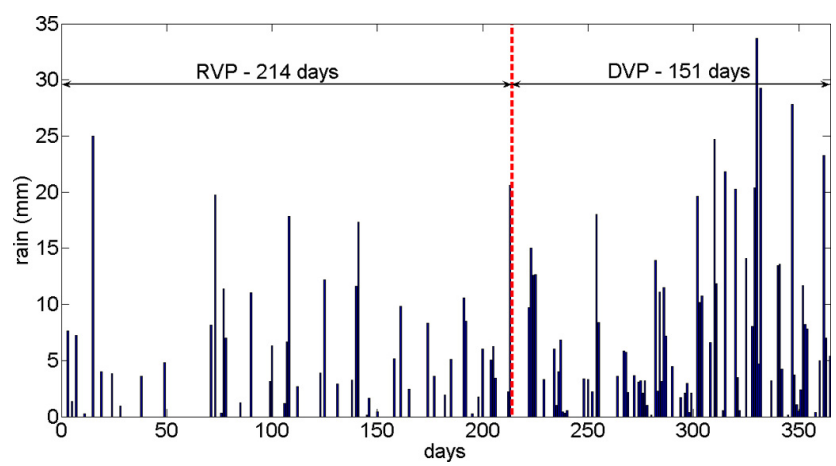

Fig. 7. Synthetic records of rainfall depth for a generic year. The red line separates the hydrologic year into the RVP and DVP seasons.

In order for the SWAP lower boundary condition to be irrelevant or not to affect too much the simulated soil-water balance in the first $1.0 \mathrm{~m}$ of rooting depth, the lower end of the flow domain is set at a depth of $z_{\text {bot }}=2.0 \mathrm{~m}$ from soil surface. The lower boundary condition is specified as the Neumann condition of free drainage, namely the unit gradient of the total hydraulic head [i.e. $\nabla(h-z)=-1$ ] applied at $z_{\text {bot }}$. Field capacity can be a representative value for the soil water content at the end of the wet season and, for both models, in the first year simulations start when the systems are at the condition of field capacity in soil at the beginning of what we assumed being the growing season (1 April). Therefore, the starting condition is the degree of soil moisture $s_{\mathrm{fc}}$ for the bucket model, and the suction head $h_{\mathrm{fc}}$, corresponding to $\theta_{\mathrm{fc}}$, for the SWAP model. In particular, for the BM model the initial soil-water storage capacity, $\mathrm{WS}_{\mathrm{ini}}=s_{\mathrm{fc}} \times n \times Z_{\mathrm{r}}$, 
represents a relatively wet condition for the soil-vegetation system and the relevant values are reported in Table 4 for the two soil types and the two different techniques to determine soil moisture at field capacity. To lessen or remove the effects of the initial conditions on the intercomparison results, the first year of simulation is taken as a sort of spin-up time and removed from the subsequent analyses. Therefore, the actual initial condition is the state of the system at the end of this first year of preliminary simulation. Apart from other forcing variables, a spin-up time for soil moisture varies with the thickness of soil profile: the deeper the soil depth is, the longer the soil moisture reaches its equilibrium state. By running several simulations with different initial conditions, we observed that the results were independent from the initial condition after the first year.

\subsection{Performance measures}

We have selected the mean error (ME) and the root-meansquare error (RMSE) as performance measures, which are computed using the following equations:

$\mathrm{ME}=\frac{\sum_{i=1}^{N} \operatorname{err}_{i}}{N}$

RMSE $=\sqrt{\frac{\sum_{i=1}^{N}\left(\operatorname{err}_{i}\right)^{2}}{N}}$

where $N$ is the total number of data and $\operatorname{err}_{i}=\left(v_{i}^{\text {SWAP }}-\right.$ $v_{i}^{\mathrm{BM}}$ ) represents the deviation between the generic variable, $v_{i}^{\text {SWAP, }}$, computed by the RE-based SWAP model (assumed as a reference) and the corresponding variable, $v_{i}^{\mathrm{BM}}$, computed by the BM model. The ME statistic reveals the presence of biases (a positive value means that on average the bucket model underestimates) and is a measure of accuracy. The RMSE statistic is a commonly used measure of precision. Both ME and RMSE are dimensional indices and their best values are zero. A feature of RMSE statistic is that it tends to emphasize larger values in a series, whereas lower values are virtually neglected.

\section{Results of the numerical experiments and discussion}

Using the parameterization strategy outlined in Sect. 3, for the loamy-sand and the clay soils described in Sect. 2.3 we have compared the BM's hydrologic responses to those of the RE-based SWAP model when in BM the degree of soil saturation at field capacity, $s_{\mathrm{fc}}$, is either determined from a field drainage experiment (drain-method) or estimated as a prefixed point of the soil water retention characteristic (fixmethod).

Simulations refer to a well vegetated landscape, and therefore transpiration is assumed to be dominant to evaporation within the evapotranspiration processes (i.e. $E_{\max } \approx 0$ ). A preliminary check was carried out to ensure that the generated daily rainfall rate, $r$, never exceeds the saturated hydraulic conductivity, $K_{\mathrm{s}}$, so as to avoid that the occurrence of surface runoff might have led to difficulties when comparing the BM and RE-based SWAP performances, and hence to have better similarity among the responses offered by these two hydrologic models.

The selected performance indices are reported in Table 5 and show relatively good agreements between the BM and RE outputs, with ME and RMSE absolute values ranging around an order of some percent unit. The worst accuracy $(\mathrm{ME}=3.1 \%)$ and precision $(\mathrm{RMSE}=12.0 \%)$ for the bucket model occur when field capacity of the loamy-sand soil is determined by the fix-method. Both these largest ME and RMSE values refer to the simulation of leaching rates evolving during the dormant vegetation period and are indication of certain underestimations and wider spread of the loss fluxes computed by BM. Based on the ME index, parameterizing $s_{\mathrm{fc}}$ of the loamy-sand soil with the drain-method (see Table 5) leads almost always to the least biased responses. This occurs not only for the entire hydrologic year, but also for both RVP and DVP periods. The type of biases with respect to the reference SWAP model depends on the type of variable considered. BM systematically overestimates transpiration rate and underestimates leaching rate. In the case of soil moisture the bias behavior is different since there is an underestimation for the drain-method, but an overestimation when the fix-method is used. Only for the DVP period of soil moisture variable, the bias in absolute terms is more favorable when the fix-method is used to estimate field capacity. In terms of RMSE (see Table 5), the determination of $s_{\mathrm{fc}}$ with the drain-method increases the precision of BM responses significantly over the entire hydrologic year: for the loamy-sand soil, there are reductions in RMSE values of about $57.1 \%$ for soil moisture, $33.3 \%$ for transpiration rate, and $44.6 \%$ for draining rate. When splitting the hydrologic year into the two different periods, the reductions in RMSE values are still evident over the RVP period for all of the three variables, but for the DVP period the advantage of the drainmethod is much less evident for transpiration rate.

These comparisons among the index values help in understanding under what circumstances the different methods of parameterization of field capacity can lead to better or poorer performances of the bucket model. With respect to soil texture, overall the water balance in coarser soils feels more the positive effect of determining the field capacity value through a more rigorous method such as the drain-method. When considering seasonality, the dry season of vegetation regrowth (RVP period) appears more sensitive than the wet dormant season (DVP period) to the drain-method of parameterizing field capacity soil moisture.

Probability density functions (PDFs) of relative soil moisture, $p(s)$, obtained using the two hydrologic models and for the two sub-periods of the hydrologic year are depicted in 
Table 5. Performance indices for the loamy-sand (LS) and clay $(\mathrm{Cl})$ soil.

\begin{tabular}{|c|c|c|c|c|c|c|c|c|c|}
\hline & \multicolumn{3}{|c|}{ Soil moisture } & \multicolumn{3}{|c|}{ Transpiration rate } & \multicolumn{3}{|c|}{ Leaching rate } \\
\hline & Year & RVP & DVP & Year & RVP & DVP & Year & RVP & DVP \\
\hline & \multicolumn{9}{|c|}{ LS, drain-method } \\
\hline $\mathrm{ME}$ & $1.0 \mathrm{E}-02$ & $6.2 \mathrm{E}-03$ & $1.7 \mathrm{E}-02$ & $-6.7 \mathrm{E}-03$ & $-1.0 \mathrm{E}-02$ & $-2.1 \mathrm{E}-03$ & $9.9 \mathrm{E}-03$ & $8.7 \mathrm{E}-03$ & $1.2 \mathrm{E}-02$ \\
\hline \multirow[t]{2}{*}{ RMSE } & $2.4 \mathrm{E}-02$ & $2.2 \mathrm{E}-02$ & $2.7 \mathrm{E}-02$ & $4.8 \mathrm{E}-02$ & $6.2 \mathrm{E}-02$ & $1.1 \mathrm{E}-02$ & $4.6 \mathrm{E}-02$ & $2.4 \mathrm{E}-02$ & $6.5 \mathrm{E}-02$ \\
\hline & \multicolumn{9}{|c|}{ LS, fix-method } \\
\hline ME & $-1.3 \mathrm{E}-02$ & $-1.6 \mathrm{E}-02$ & $-8.1 \mathrm{E}-03$ & $-1.8 \mathrm{E}-02$ & $-2.9 \mathrm{E}-02$ & $-2.1 \mathrm{E}-03$ & $1.8 \mathrm{E}-02$ & $9.7 \mathrm{E}-03$ & $3.1 \mathrm{E}-02$ \\
\hline \multirow[t]{2}{*}{ RMSE } & $5.6 \mathrm{E}-02$ & $5.9 \mathrm{E}-02$ & $5.2 \mathrm{E}-02$ & $7.2 \mathrm{E}-02$ & $9.4 \mathrm{E}-02$ & $1.1 \mathrm{E}-02$ & $8.3 \mathrm{E}-02$ & $3.1 \mathrm{E}-02$ & $1.2 \mathrm{E}-01$ \\
\hline & \multicolumn{9}{|c|}{$\mathrm{Cl}$, drain-method } \\
\hline $\mathrm{ME}$ & $9.1 \mathrm{E}-03$ & 7.1E-03 & $1.1 \mathrm{E}-02$ & $-9.0 \mathrm{E}-04$ & $-1.9 \mathrm{E}-04$ & $-2.1 \mathrm{E}-03$ & $8.3 \mathrm{E}-03$ & $6.9 \mathrm{E}-03$ & $9.0 \mathrm{E}-03$ \\
\hline \multirow[t]{2}{*}{ RMSE } & $1.9 \mathrm{E}-02$ & $1.9 \mathrm{E}-02$ & $2.0 \mathrm{E}-02$ & $4.2 \mathrm{E}-02$ & $5.2 \mathrm{E}-02$ & $1.1 \mathrm{E}-02$ & $3.9 \mathrm{E}-02$ & $1.7 \mathrm{E}-02$ & $5.8 \mathrm{E}-02$ \\
\hline & \multicolumn{9}{|c|}{$\mathrm{Cl}$, fix-method } \\
\hline ME & $9.4 \mathrm{E}-03$ & $7.2 \mathrm{E}-03$ & $1.3 \mathrm{E}-02$ & $-9.4 \mathrm{E}-04$ & $-2.0 \mathrm{E}-04$ & $-2.0 \mathrm{E}-03$ & $8.4 \mathrm{E}-03$ & $7.0 \mathrm{E}-03$ & $1.0 \mathrm{E}-02$ \\
\hline RMSE & $2.0 \mathrm{E}-02$ & $1.8 \mathrm{E}-02$ & $2.2 \mathrm{E}-02$ & $4.1 \mathrm{E}-02$ & $5.3 \mathrm{E}-02$ & $1.0 \mathrm{E}-02$ & $4.1 \mathrm{E}-02$ & $1.8 \mathrm{E}-02$ & $5.9 \mathrm{E}-02$ \\
\hline
\end{tabular}

the Fig. 8. For the loamy-sand soil the top plots refer to the RVP (panel a) and DVP (panel b) sub-periods of the hydrologic year, whereas the bottom plots refer again to the RVP (panel c) and DVP (panel d) sub-periods but for the clay soil. The shapes of the $p(s)$ functions are clearly affected by the climatic forcing imposed during the two different RVP and DVP periods. Comparisons when moving horizontally on Fig. 8 (i.e. from a to $b$, or from $c$ to d) provide evidence of the occurrence of different seasonal dynamics of the average soil moisture in the active soil profile, with vegetation that modulates interstorm soil moisture redistribution. Note that the $p(s)$ functions of Fig. 5c-d are shifted towards the higher $s$ values because of the hydraulic properties of the clay soil, but the general shapes of the PDFs remain nearly unchanged with respect to the effects of both seasonal changes (horizontal comparisons) and field capacity parameterization (drainmethod vs. $f i x$-method, i.e. blue solid lines vs. green dotted lines).

Although soil moisture content is obviously bounded between the permanent wilting and porosity points of the specific soil type, the single-peaked $p(s)_{\mathrm{RVP}}$ functions of the drier RVP period (Fig. 5a or 5c) have the typical shape of a system characterized by a relatively deep soil profile and low mean rainfall rate (i.e. a low PRP parameter $\lambda$ ). These $p(s)_{\mathrm{RVP}}$ functions are positively skewed and narrow distributions, with relative soil moisture contents that vary in a small range around the peak and show quite long tails starting soon after the relative soil moisture point $s^{*}$ of incipient stomata closure. The modal value located close to the wilting point corresponds to the preferred state over the main part of the RVP, whereas the succeeding long tail located in the right side of the plot is representative of the fast transition from a wet state at the end of the dormant season toward a nearly dry stationary state. During this vegetative (re-)growing period, vegetation transpiration dominates the water balance and controls soil moisture contents in the active soil zone, which are consistently low. Consequently, leakage becomes a negligible process. For the fraction of the hydrologic year corresponding to the wetter DVP period (Fig. 5b and 5d), the fluctuation of precipitation and storage capacity of soil are perceived to dominate over the smaller amount of transpiration and to exert a remarkable control on soil moisture variability over time. Most of the soil water stored in the system results in unstressed evapotranspiration. The different precipitation regime and transpiration characteristics of this period basically make the $p(s)_{\text {DVP }}$ functions to be broader than those of the previous case and more concentrated around $s$ values near the field capacity point, $s_{\mathrm{fc}}$.

To better frame the results depicted in Fig. 8, a quantitative but simple analysis can be carry out for identifying under which conditions the soil moisture at field capacity, $s_{\mathrm{fc}}$, can play a more dominant role in the computation of soil water balance. This analysis is particularly relevant to the objective of the present study since this role can have different features depending on the season (e.g. the RVP phase) of the entire hydrologic year one is dealing with. In single-layer buckettype models, soil moisture depletes almost immediately due to the evapotranspiration process and is replenished when precipitation occurs. Allowing for seasonality, depletion and replenishment of soil moisture can be faster or slower depending on the specific exchanges between atmosphere and soil during the considered period of the year. An evaluation 

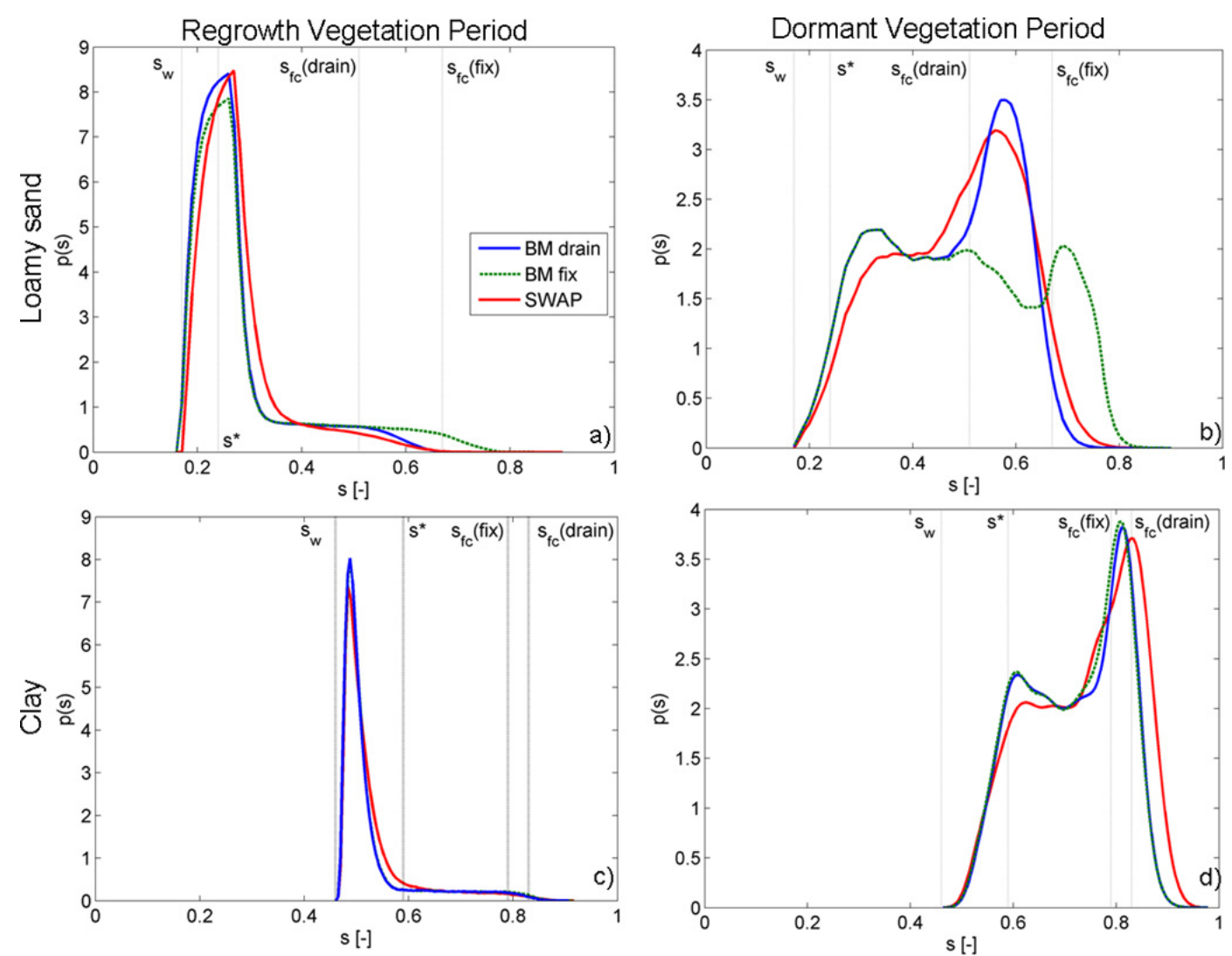

Fig. 8. Probability density functions of relative soil moisture content, $s$, for the loamy-sand soil (5a and $5 b$ ) and for the clay soil (5c and $5 d$ ). The plots on the left-hand-side refer to the RVP season, whereas the plots of the right-hand side refer to the DVP season. Red solid lines are the SWAP model results used as a reference; blue solid lines refer to BM when field capacity is parameterized with the drain-method; green dotted lines refer to BM when field capacity is parameterized with the fix-method.

of the response timescales of soil moisture in the root zone can help in gaining a better understanding of the model comparisons presented in this study.

The evolution of the dry RVP season depletes soil moisture from the rooting zone as precipitation falls only over a small fraction of this period. The depletion time indicates how long it would take the maximum plant-available soilwater holding capacity, PAWS $S_{\max }=\left(s_{\mathrm{fc}}-s_{\mathrm{W}}\right) \times n \times Z_{\mathrm{r}}$, of the soil-vegetation system to dry out subject to the net outflow, $R_{\mathrm{d}}=\mathrm{ET}_{\text {max }}-P$, between maximum evapotranspiration and mean precipitation rates $(P=\eta \cdot \lambda)$, that remains constant and not considering other fluxes (Beljaars et al., 1996; Viola et al., 2008). In a similar way, we can define a replenishment timescale of the soil bucket during the DVP season assuming that the term $R_{\mathrm{r}}=P-\mathrm{ET}_{\max }$ remains constant throughout that period. Accordingly, the depletion time, $t_{\mathrm{d}}$, and the replenishment time, $t_{\mathrm{r}}$, give an indication of average moisture residence time in the soil and are calculated as follows:

$t_{\mathrm{d}}=\frac{\text { PAWS }_{\max }}{R_{\mathrm{d}}}$,

$t_{\mathrm{r}}=\frac{\mathrm{PAWS}_{\mathrm{max}}}{R_{\mathrm{r}}}$.
These two timescales are in Table 6, which also reports the ratios $\rho_{\mathrm{d}}$ and $\rho_{\mathrm{r}}$ that relate the depletion and replenishment times to the durations of the RVP (214 days) and DVP (151 days) seasons, respectively. The values of ratio $\rho_{\mathrm{d}}$ are fairly similar among them and show that depletion times are approximately $25 \%$ or $20 \%$, depending on the specific soil type, of the total length of the dry RVP season and this situation, from the one hand, justifies the presence of the extended tails in the soil moisture probability density functions, $p(s)$ (see Fig. 8a and b). On the other hand, however, it indirectly suggests that the amount of water stored in soil is relatively small for most of this dry period and hence field capacity becomes a parameter that can exert a more limited influence on the computation of soil water balance.

Looking at the wet DVP season, the $\rho_{\mathrm{r}}$ values clearly indicates that now soil moisture stored in the bucket capacity is high over periods commensurate to the length of the DVP season. Therefore, one would expect that field capacity will play a more relevant role when computing the soil water balance during a wetter season. Consequently, and in a way consistent with the results depicted in Fig. 8, the greater the discrepancies between field capacity values as determined by 
Table 6. Characteristic time scales of the bucket model during the DVP and RVP periods computed for the loamy-sand (L-S) and the clay (Cl) soils.

\begin{tabular}{|c|c|c|c|c|c|c|}
\hline \multirow[t]{2}{*}{ Soil texture } & \multirow[t]{2}{*}{ Method } & \multirow[t]{2}{*}{ PAWS $_{\max }(\mathrm{cm})$} & \multicolumn{2}{|c|}{$\operatorname{RVP}\left(214\right.$ days, $\left.R_{\mathrm{d}}=0.344 \mathrm{~cm} \mathrm{~d}^{-1}\right)$} & \multicolumn{2}{|c|}{ DVP $\left(151\right.$ days, $\left.R_{\mathrm{r}}=0.146 \mathrm{~cm} \mathrm{~d}^{-1}\right)$} \\
\hline & & & $t_{\mathrm{d}}$ (days) & $\rho_{\mathrm{d}}(\%)$ & $t_{\mathrm{r}}$ (days) & $\rho_{\mathrm{r}}(\%)$ \\
\hline \multirow[t]{2}{*}{ LS } & drain $^{\mathrm{a}}$ & 15.24 & 44.3 & 20.7 & 104.7 & 69.3 \\
\hline & $f i x^{\mathrm{b}}$ & 22.39 & 65.1 & 30.4 & 153.8 & 101.9 \\
\hline \multirow[t]{2}{*}{$\mathrm{Cl}$} & $\operatorname{drain}^{\mathrm{a}}$ & 15.76 & 45.8 & 21.4 & 108.3 & 71.7 \\
\hline & $f i x^{\mathrm{c}}$ & 14.06 & 40.9 & 19.1 & 96.6 & 63.9 \\
\hline
\end{tabular}

${ }^{\mathrm{a}}$ drain $=s_{\mathrm{fc}}$ defined by the drainage experiment; ${ }^{\mathrm{b}}$ fix $=s_{\mathrm{fc}}$ from Eq. $(2 \mathrm{a})$ at $h=100 \mathrm{~cm} ;{ }^{\mathrm{c}} f i x=s_{\mathrm{fc}}$ from Eq. $(2 \mathrm{a})$ at $h=500 \mathrm{~cm}$.

the drain-method or the fix-method (and this happens for the loamy-sand soil; see plots 5a and 5b), the worse appear the comparisons between the BM and RE-SWAP models. This discussion provides a more quantitative perspective of our results and also reinforces the significance of the performance indices reported in Table 5. By dwelling on relative soil moisture over the DVP season, we have a reduction in RMSE between the two methods of about $48.1 \%$ for the loamysand soil and of about $9.1 \%$ for the clay soil. Instead, for the leaching rates computed over the DVP season there are RMSE reductions of about $45.8 \%$ and $1.7 \%$ for the LS and $\mathrm{Cl}$ soils, respectively. As expected, transpiration rates over the DVP season (but over the RVP season, too) as computed by $\mathrm{BM}$ are less affected by the techniques used to determine the value of soil moisture at field capacity, $s_{\mathrm{fc}}$.

It is worth noting that the $p(s)_{\text {DVP }}$ distributions clearly show a propensity for a temporal bimodality. The DVP bimodal distribution is characterized by two preferential soil moisture states: a more pronounced peak, to which higher probability is attached, is at around the field capacity value, while another peak is located in proximity to $s^{*}$ (depending on soil texture). The occurrence of bimodality in the probability distribution of relative soil moisture has been observed and discussed by several researchers (e.g. Kochendorfer and Ramírez, 2005; Daly et al., 2009; Vivoni et al., 2010), also with different views. D'Odorico and Porporato (2004) reinforced previous ideas that a bimodal PDF of soil moisture measurements over the summer season in the continental region of Illinois provided evidence of a soil moisture-rainfall feedback mechanism. Instead, Teuling et al. (2005) argued that an explanation of the soil moisture bimodality observed in Illinois should be the seasonality in meteorological forcing and the nonlinearity of the soil moisture loss function. The data set used by Lee and Hornberger (2006) did not permit to single out any of these hypotheses as the cause for bimodality, and these authors also warned about not making any causality claim since that requires strong statistical support. With specific reference to the stochastic generation of temporal precipitation fields, Porporato and D'Odorico (2004) have put forward the hypothesis that Poisson-type noises applied to a nonlinear system can induce, among other things, a temporal persistence around preferential states and hence a bimodality in the probability density function of relative soil moisture time-series. In this case, the variability of precipitation imposed during the DVP season, and specifically the frequency of storm occurrence, can result in the bimodal shape of the $p(s)_{\text {DVP }}$ distributions depicted in Fig. 8. Overall, the soil moisture probability distributions in the plots $5 \mathrm{~b}$ and $5 \mathrm{~d}$ show that during the DVP period the soil, it being of coarser or finer texture, can preferentially be in either wet states close to field capacity, or relatively drier states closer to the incipient stomata closure. In other words, the bimodality observed in the DVP is representative of two dominant states: one during the transition stage from the dry season to the wet season, when there is a rapid increase of the saturation degree above the stress value threshold; the other corresponding to a stationary wet state.

With respect to the two different methods to determine parameter $s_{\mathrm{fc}}$, the soil moisture PDFs of Fig. 8 help in identifying under what circumstances might it be appropriate to use the fix-method to parameterize the bucket model. Compared to the SWAP reference model, the performances of the bucket model are acceptable only when one refers to the RVP period (plots $8 \mathrm{a}$ and $8 \mathrm{c}$ ). It is interesting to note that this behavior occurs independently from the textural properties of the soils considered, but this is also partly due to the narrow shape of the soil moisture probability distributions over the considered regrowing season. In accordance to the performance indices of Tables 1 and 2 and as one would expect, the larger discrepancies between SWAP and BM during the RVP period occur for the loamy-sand soil and when adopting the fix-method for estimating $s_{\mathrm{fc}}$. Instead, the plots $5 \mathrm{~b}$ and $5 \mathrm{~d}$ pertaining to the dormant and wetter season (DVP period) overall show rather poor performances of the bucket model especially when $s_{\mathrm{fc}}$ is estimated by the $f i x$-method and for the coarser soil (Fig. 5b).

In general terms, determining the field capacity soil moisture by the traditionally-proposed technique of a prefixed point of the water retention function results in discrepancies with respect to the reference RE-based SWAP model of different extents depending on the soil type and the period of the hydrologic year. Errors become quite unacceptable when 

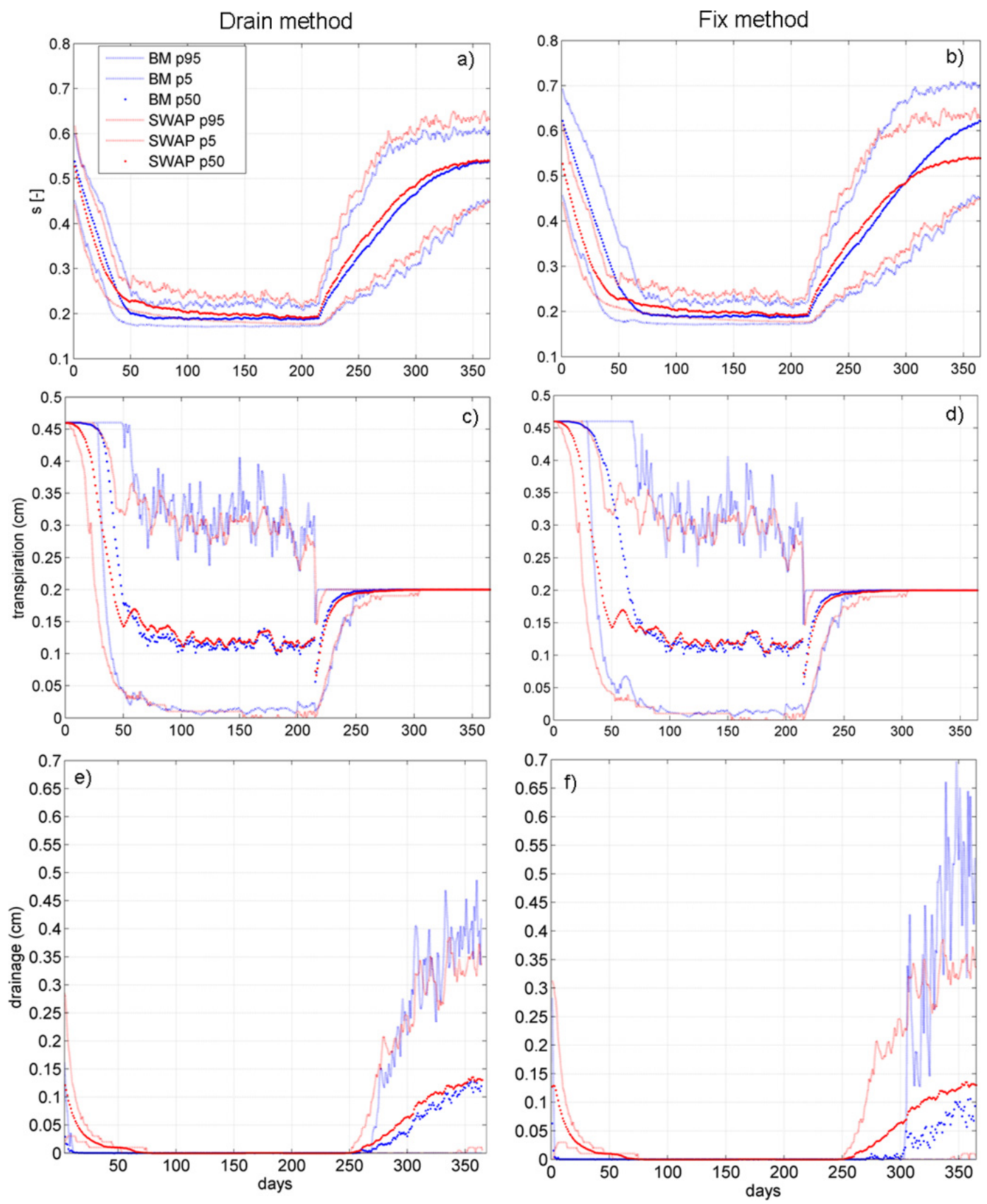

Fig. 9. Daily values of the 5th, 50th, and 95th quantiles for the loamy-sand soil over the entire hydrologic year as obtained from the 99 years of simulation run. Red lines refer to the SWAP model used as a reference, while blue lines refer to BM when field capacity is parameterized either with the drain-method (plots on the left-hand side) or with the fix-method (plots on the right-hand side): (a) and (b) refer to relative soil moisture content, $s$; (c) and (d) refer to daily transpiration fluxes, $T$; (e) and (f) refer to daily drainage (leakage) fluxes, $L$.

one would capture soil moisture dynamics in coarser soils and in the rainiest season of a Mediterranean climatic area.

All the above comments and discussions are also clearly reflected in the representation of Fig. 9 showing the 5th, 50th, and 95th quantiles of relative soil moisture content, $s$, over the entire hydrologic year as obtained from the 99 years of simulation run. The various plots of this figure pertain to the loamy-sand soil only as all the results discussed before have clearly shown that the main discrepancies when BM is differently parameterized occur for coarser textured soils. The left plots of Fig. 9 (namely 9a-c-e) depict the simulation results when field capacity of BM is determined by the drain-method; the right plots (9b-d-f) represent the simulation results when field capacity of BM is estimated by the 
fix-method. In accordance to the performance indicators of Tables 1 and 2, we observe that the loamy-sand soil of this study is remarkably affected by the method used to determine the field capacity parameter, $s_{\mathrm{fc}}$, and that there is also a change in the magnitude of bias in different parts of the hydrologic year. Specifically, when the fix-method is employed to estimate $s_{\mathrm{fc}}$, the bucket model systematically underestimates the simulated soil moisture during the first nearly 5060 days of the year, namely from beginning of April to approximately the end of June, as well as when approaching the period February-March. In practice, when field capacity is parameterized by the $f i x$-method, BM is unable to reproduce the reference storage capacity variations during the periods characterized by highest relative soil moisture values. Better agreements between the RE-SWAP and BM results are observed for this coarser loamy-sand soil only when relative soil moisture attains its lowest values and reaches the permanent wilting point.

One should note that the impacts on relative soil moisture of how to determine the BM parameter $s_{\mathrm{fc}}$ do not necessarily imply similar impacts on water fluxes. Seasonal variations of simulated daily transpiration and drainage (leakage) fluxes outgoing from the system are shown in Fig. 9c-d and $9 \mathrm{e}-\mathrm{f}$, respectively, when using either the drain- or fix-method to determine the field capacity parameter $s_{\mathrm{fc}}$. Regardless of the method employed to determine $s_{\mathrm{fc}}$ (but also regardless the soil types considered, although not shown as said before) the bucket model outputs are not able to capture the temporal evolution of transpiration and leakage losses from the Richards equation based model over both the RVP and DVP seasons. Larger discrepancies between simulated BM and RE-SWAP transpiration fluxes are observed during the RVP season of the hydrologic year, especially at the highest soil moisture contents, and this represents a visual evidence of the performance indices of Table 5 as well as is in accordance with the preceding discussion about the role of the field capacity parameter in the computation of the seasonal water balance by a single-layer bucket-type model. At the beginning of the RVP season soil tends to be at the condition of field capacity and the discrepancies of $\mathrm{BM}$ with respect to $\mathrm{RE}$ are soon evident, especially when $s_{\mathrm{fc}}$ is estimated through the fix-method (see Fig. 9d during the first 60-70 days of simulation). The RVP climate conditions induce a rapid soil moisture depletion, as we have discussed before and shown in Table 6, and this decrease in $s$ as time increases starts earlier and is somewhat more rapid for the bucket model as its memory capability is small (i.e. its response is fairly rapid to climatic forcing) compared to that one offered by the Richards model. This can be viewed as a major reason for the temporal lags observed in Fig. 9c and d between the BM and RE-SWAP models over the first stage of the RVP season. Another explanation for the observed time-shift between BM and RE-SWAP transpiration fluxes at the end of the wet season/beginning of dry season can of course be also attributed to the differences in the transpiration functions, $T(s)$, shown in Fig. 3. In general, the time variations of transpiration fluxes as computed by BM during RVP are in agreement with those from the Richards equation only when soil moistures start attaining lower values and close to the critical moisture value $s^{*}$ : the drier are moisture conditions in this soil, the better BM transpiration fluxes follow the time fluctuations of the RE-computed fluxes. Overall, the discussed outcome again reinforces the need and the importance of accounting for local seasonal conditions to evaluate the effectiveness of using one modeling scheme of a soil-vegetation system with respect to another. Comparisons appear to be more satisfactory during the DVP period even when the values of $s$ are relatively low. As expected, larger deviations of the BM losses from leakage occur for the loamy-sand soil and during the colder and rainier season straddling over the end of the DVP period and the beginning of the RVP period. The BM modeling scheme tends to underestimate leakage losses over both the RVP and DVP seasons (see also the positive ME values in Table 5 for this loamy-sand soil), with larger discrepancies with respect to RE-SWAP occurring over the DVP season since leakage becomes important under high $s$-values. It is worth mentioning again that DVP is a relatively wetter season, with greater soil moisture values almost throughout the period and hence more prone to failure in the model intercomparison because of the differently estimated values for the field capacity parameter.

\section{Conclusions}

Bucket models are widely used tools to represent land surface hydrology, usually at regional scales, mainly because they account for soil water changes in a relatively simple way. However, since soil water is a key regulator of primary hydrologic processes, a careful parameterization of these capacitance models is a crucial phase. We have shown that the commonly used approach to estimate the field capacity at a specific point of the water retention curve (usually as the soil water content at the suction head of $3.3 \mathrm{~m}$ ) might lead in general to poorer predictions of the various terms contributing to the soil-water budget, particularly for coarsetextured soils. Allowing for the key role that field capacity plays in bucket models, it is advisable that this parameter is determined via a field drainage experiment (drain-method). This suggestion is particularly relevant if one would employ a bucketing approach for modeling soil water budget in areas with a climatic regime characterized by marked seasonality. Our study has also emphasized the benefit of looking at the parameterization problem also by carrying out functional evaluations. Through numerical simulations and intercomparisons between the bucket model (BM) and Richards' equation based SWAP model (RE-SWAP), one can see that larger discrepancies should be expected when dealing with coarser soils and field capacity for this soil type is parameterized using the water retention curve (fix-method). Of specific 
interest and a novelty, as far as we are concerned, is the possibility to further frame this outcome while considering a seasonality in the input climatic forcing. At least for the cases considered in this study, the bucket model with field capacity as determined by the fix-method provides some relatively good predictions preferably when considering finer textured soils and when soil-water balance refers to a drier season of the hydrologic year and vegetation is in under a regrowing stage (RVP period). It is important to point out, however, that the way with which we have parameterized both BM and SWAP is such so as to make boundary conditions and transpiration functions as similar as possible and to perform effective intercomparisons. Finally, analyses of the probability density functions of relative soil moisture content have highlighted the possible occurrence of bimodality in the shape of curves during the dormant vegetation phase as result of the combination of a dry-to-wet transition and a wetter state in the soil. A discussion on this bimodality is far from the purpose of this paper and it can be the subject of a subsequent study.

\section{Appendix A}

\section{Abbreviations}

BM, bucket model; RE, Richards' equation; SWAP, Soil Water Atmosphere Plant model; DVP, dormant vegetation phase; RVP, regrowth vegetation phase; ME, mean error; RMSE, root-mean-square error.

Acknowledgements. This work profited from the analyses carried out by Francesca Ceres during her doctoral period. The authors thank A. J. Guswa for having kindly provided the code and information about the bucket model, as well as for his thorough evaluation and helpful comments. His suggestion of considering characteristic depletion and replenishment times was greatly appreciated. We also thank R. S. Crosbie, L. Peeters and two additional anonymous reviewers for their recommendations and constructive criticisms that have helped to improve this manuscript.

Edited by: H. H. G. Savenije

\section{References}

Beljaars, A. C. M., Viterbo, P., Miller, M. J., and Betts, A. K.: The anomalous rainfall over the United States during July 1993: Sensitivity to land surface parameterization and soil moisture anomalies, Mon. Weather Rev., 124, 362-383, 1996.

Beven, K. J.: Changing ideas in hydrology - The case of physicallybased models, J. Hydrol., 105, 157-172, 1989.

Blöschl, G. and Montanari, A.: Climate change impacts - throwing the dice?, Hydrol. Processes, 24, 374-381, 2010.

Braud, I.: Spatial variability of surface properties and estimation of surface fluxes of a savannah, Agric. Forest Meteorol., 89, 15-44, 1998.
Ceres, F.: Parameterizing hydrologic models for the management of agro-forestry systems. Ph.D. dissertation, 187 pp., University of Naples Federico II, available on-line at www.unina.it, 2009 (in Italian).

Ceres, F., Chirico, G. B., and Romano, N.: Functional evaluation of the field capacity concept for water balance analysis under climatic seasonality condition, 2010 General Assembly of EGU, EGU2010-2901, Vienna, 2-7 May 2010.

Clark, M. P., Slater, A. G., Rupp, D. E., Woods, R. A., Vrugt, J. A., Gupta, H. V., Wagener, T., and Hay, L. E.: Framework for understanding structural errors (FUSE): A modular framework to diagnose differences between hydrological models, Water Resour. Res., 44, W00B02, doi:10.1029/2007WR006735, 2008.

Daly, E., Zinger, Y., Deletic, A., and Fletcher, T. D.: A possible mechanism for soil moisture bimodality in humid-land environments, Geophys. Res. Lett., 36, L07402, doi:10.1029/2008GL036933, 2009.

de Jong van Lier, Q., Dourado Neto, D., and Metselaar, K.: Modeling of transpiration reduction in van GenuchtenMualem type soils, Water Resour. Res., 45, W02422, doi:10.1029/2008WR006938, 2009.

Denmead, O. T. and Shaw, R. H.: Availability of soil water to plants as affected by soil moisture content and meteorological conditions, Agron. J., 54, 385-390, 1962.

D'Odorico, P. and Porporato, A.: Preferential states in soil moisture and climate dynamics, Proc. Natnl. Acad. Sci., 101, 8848-8851, 2004.

Farmer, D., Sivapalan, M., and Jothityangkoon, C.: Climate, soil, and vegetation controls upon the variability of water balance in temperate and semiarid landscapes: Downward approach to water balance analysis, Water Resour. Res., 39, 1035, doi:10.1029/2001WR000328, 2003.

Feddes, R. A., Hoff, H., Bruen, M., Dawson, T., de Rosnay, P., Dirmeyer, P., Jackson, R. B., Kabat, P., Kleidon, A., Lilly, A., and Pitman, A. J.: Modeling root water uptake in hydrological and climate models, B. Am. Meteorol. Soc., 82, 2797-2809, 2001.

Guswa, A. J., Celia, M. A., and Rodriguez-Iturbe, I.: Models of soil moisture dynamics in ecohydrology: A comparative study, Water Resour. Res., 38, W01166, doi:10.1029/2001WR000826, 2002.

Holländer, H. M., Blume, T., Bormann, H., Buytaert, W., Chirico, G. B., Exbrayat, J.-F., Gustafsson, D., Hölzel, H., Kraft, P., Stamm, C., Stoll, S., Blöschl, G., and Flühler, H.: Comparative predictions of discharge from an artificial catchment (Chicken Creek) using sparse data, Hydrol. Earth Syst. Sci., 13, 20692094, doi:10.5194/hess-13-2069-2009, 2009.

Horton, R. E.: Surface runoff phenomena: I. Analysis of the hydrograph, Horton Hydrol. Lab. Pub. 101, Vorheesville, N.Y., 73 pp., 1935.

Kochendorfer, J. P. and Ramírez, J. A.: The impact of land atmosphere interactions in the temporal variability of soil moisture, J. Hydrometeorology, 6, 53-67, 2005.

Kowalczyk, E. A., Wang, Y. P., Law, R. M., Davies, H. L., McGregor J. L., and Abramowitz, G.: The CSIRO Atmosphere Biosphere Land Exchange (CABLE) model for use in climate models and as an offline model, CSIRO Marine and Atmospheric Research, Paper \#13, 257 pp., 2006.

Kroes, J. G. and van Dam, J. C.: Reference Manual SWAP version 3.0.3, Wageningen, Alterra, Green World Research, Alterrareport 773, 211 pp., 2003. 
Kutílek, M. and Nielsen, D. R.: Soil Hydrology. GeoEcology Textbook, Catena Verlag, Cremlingen-Destedt, Germany, 1994.

Laio, F., Porporato, A., Ridolfi, L., and Rodriguez-Iturbe, I.: Plants in water controlled ecosystems: Active role in hydrological processes and response to water stress, II. Probabilistic soil moisture dynamics, Adv. Water Resour., 24, 707-723, 2001.

Lee, D. H. and Abriola, L.: Use of the Richards equation in land surface parameterizations, J. Geophysical Res., 104, 519-526, 1999.

Lee, T. R. and Hornberger, G. M.: Inferred bimodality in the distribution of soil moisture at Big Meadows, Shenandoah National Park, Virginia, Geophys. Res. Lett., 33, L06407, doi:10.1029/2005GL025536, 2006.

Manabe, S.: The atmospheric circulation and the hydrology of the earth's surface, Mon. Weather Rev., 97, 739-774, 1969.

Manus, C., Anquetin, S., Braud, I., Vandervaere, J.-P., Creutin, J.D., Viallet, P., and Gaume, E.: A modeling approach to assess the hydrological response of small mediterranean catchments to the variability of soil characteristics in a context of extreme events, Hydrol. Earth Syst. Sci., 13, 79-97, doi:10.5194/hess13-79-2009, 2009.

Meyer, P. D. and Gee, G. W.: Flux-based estimation of field capacity, J. Geotechnical Geoenvironmental Engineering, 125, 595599, 1999.

McDonnell, J. J., Sivapalan, M., Vaché, K., Dunn, S., Grant, G., Haggerty, R., Hinz, C., Hooper, R., Kirchner, J., Roderick, M. L., Selker, J., and Weiler, M.: Moving beyond heterogeneity and process complexity: A new vision for watershed hydrology, Water Resour. Res., 43, W07301, doi:10.1029/2006WR005467, 2007.

Milly, P. C. D.: Climate, soil water storage, and the average annual water balance, Water Resour. Res., 30, 2143-2156, 1994.

Milly, P. C. D., Betancourt, J., Falkenmark, M., Hirsch, R. M., Kundzewicz, Z. W., Lettenmaier, D. P., and Stouffer, R. J.: Stationarity is dead: Whither water management?, Science, 319, 573-574, 2008.

Nemes, A., Wösten, J. H. M., Lilly, A., and Oude Voshaar, J. H.: Evaluation of different procedures to interpolate particle-size distributions to achieve compatibility within soil databases, Geoderma, 90, 187-202, 1999.

Nemes, A., Schaap, M. G., Leij, F. J., and Wösten, J. H. M.: Description of the unsaturated soil hydraulic database UNSODA version 2.0, J. Hydrol., 251, 151-162, 2001.

Oleson, K. W., Lawrence, D. M., Bonan, G. B., Flanner, M. G., Kluzek, E., Lawrence, P. J., Levis, S., Swenson, S. C., and Thornton, P. E.: Technical Description of version 4.0 of the Community Land Model (CLM), NCAR Technical Note, NCAR/TN478+STR, Boulder, CO, 2010.

Porporato, A. and D'Odorico, P.: Phase transitions driven by state-dependent Poisson noise, Phys. Rev. Lett., 92, 110601, doi:10.1103/PhysRevLett.92.110601, 2004.

Porporato, A., D’Odorico, P., Laio, F., Ridolfi, L., and RodriguezIturbe, I.: Ecohydrology of water-controlled ecosystems, Adv. Water Resour., 25, 1335-1348, 2002.

Pumo, D., Viola, F., and Noto, L. V.: Ecohydrology in Mediterranean areas: a numerical model to describe growing seasons out of phase with precipitations, Hydrol. Earth Syst. Sci., 12, 303316, doi:10.5194/hess-12-303-2008, 2008.
Romano, N. and Santini, A.: Determining soil hydraulic functions from evaporation experiments by a parameter estimation approach: Experimental verifications and numerical studies, Water Resour. Res., 35, 3343-3359, 1999.

Romano, N. and Santini, A.: Water retention and storage: Field, in: Methods of Soil Analysis, Part 4, Physical Methods, edited by: Dane, J. H. and Topp, G. C., 721-738, SSSA Book Series N.5, Madison, WI, USA, 2002.

Romano, N., Brunone, B., and Santini, A.: Numerical analysis of one-dimensional unsaturated flow in layered soils, Adv. Water Resour., 21, 315-324, 1998.

Seneviratne, S. I., Corti, T., Davin, E. L., Hirschi, M., Jaeger, E. B., Lehner, I., Orlowsky, B., and Teuling, A. J.: Investigating soil moisture - climate interactions in a changing climate: A review, Earth-Sci. Rev., 99, 125-161, 2010.

Settin, T., Botter, G., Rodriguez-Iturbe, I., and Rinaldo, A.: Numerical studies on soil moisture distributions in heterogeneous catchments, Water Resour. Res., 43, W05425, doi:10.1029/2006WR005737, 2007.

Sharma, M. L. and Luxmoore, R. J.: Soil spatial variability and its consequences on simulated water balance, Water Resour. Res., 15, 1567-1573, 1979.

Šimůnek, J., Šejna,, M., Saito, H., Sakai, M., and van Genuchten, M. T.: The Hydrus-1D Software Package for Simulating the Movement of Water, Heat, and Multiple Solutes in Variably Saturated Media, Version 4.0, HYDRUS Software Series 3, Department of Environmental Sciences, University of California Riverside, Riverside, California, USA, 315 pp., 2008.

Soil Science Society of America: Glossary of soil science terms. SSSA, 92 pp., Madison, WI, ISBN 978-0-89118-851-3, 2008.

Sposito, G.: The "physics" of soil water physics, Water Resour. Res., 22, 83S-88S, 1986.

Teuling, A. J., Uijlenhoet, R., and Troch, P. A.: On bimodality in warm season soil moisture observations, Geophys. Res. Lett., 32, L05404, doi:10.1029/2005GL023223, 2005.

Twarakavi, N. K. C., Sakai, M., and Šimůnek, J.: An objective analysis of the dynamic nature of field capacity, Water Resour. Res., 45, W10410, doi:10.1029/2009WR007944, 2009.

van Dam, J. C., Groenendijk, P., Hendriks, R. F. A., and Kroes, J. G.: Advances of modeling water flow in variably saturated soils with SWAP, Vadose Zone J., 7, 640-653, 2008.

Veihmeyer, F. J. and Hendrickson, A. H.: Soil moisture conditions in relation to plant growth, Plant Physiol., 2, 71-78, 1927.

Viola, F., Daly, E., Vico, G., Cannarozzo, M., and Porporato, A.: Transient soil-moisture dynamics and climate change in Mediterranean ecosystems, Water Resour. Res., 44, W11412, doi:10.1029/2007WR006371, 2008.

Vivoni, E. R., Rodríguez, J. C., and Watts, C. J.: On the spatiotemporal variability of soil moisture and evapotranspiration in a mountainous basin within the North American monsoon region, Water Resour. Res., 46, W02509, doi:10.1029/2009WR008240, 2010 . 